\title{
Information Politics and Information Culture: A Case Study
}

\author{
Bob Travica \\ University of Manitoba, Winnipeg, Canada
}

btravica@ms.umanitoba.ca

\begin{abstract}
This article introduces the concepts of information politics and information culture and presents a case study that explores these concepts. The literature from the areas of IS theory and organization theory that provides a backdrop to these concepts is discussed. A case of an organization that has characteristics of both small business and voluntary organization is presented as initial validation of the concepts of information politics and information culture. The case draws on a longitudinal interpretivist study and tracks a trajectory of organizational design, information politics, information culture, management and organizational performance over 25 months. The primary finding is that the organization studied exhibited two distinct information politics and information cultures, each related to different development phases - the era of clan and the era of teams. The article also discusses particular aspects of information politics and information culture and how these relate to organizational performance. Derived are implications for further research on information politics and information culture as well as for a broader parent framework called Information View of Organization.
\end{abstract}

Keywords: Information, knowledge, knowledge management, information technology, organizational politics, organizational culture, information politics, information culture

\section{Introduction}

The purpose of this article is to explore issues of information politics (infopolitics, for short) and information culture (infoculture). The concepts of infoculture and infopolitics were introduced by Travica (2003) as part of an information view of organization (IVO). A fundamental assumption behind IVO is that classical views of organizations, such as cultural, political, and structural one, need to be applied directly to information (broadly conceptulized) and information technology (IT). (Note that the term information is used here in a broad sense to mean knowledge, organized/meaningful data or meaning, and data; when the phrase "information and knowledge" is used, "information" means "organized/meaningful data/meaning"). The corollary is that information and IT have a prominent cultural, political, and structural existence, which complements,

Material published as part of this journal, either on-line or in print, is copyrighted by the publisher of the Informing Science Journal. Permission to make digital or paper copy of part or all of these works for personal or classroom use is granted without fee provided that the copies are not made or distributed for profit or commercial advantage AND that copies 1) bear this notice in full and 2) give the full citation on the first page. It is permissible to abstract these works so long as credit is given. To copy in all other cases or to republish or to post on a server or to redistribute to lists requires specific permission and payment of a fee. Contact Editor@inform.nu to request redistribution permission. influences, and is influenced by organizational culture, politics, structure, and other aspects.

While borrowing liberally from organization theory, the home of IVO is in the IS field. IVO brings IS phenomena to the forefront and demonstrates that these are inextricably coupled with organizational aspects. In addition, IVO intends to introduce a unified vocabulary that would clearly 
indicate links between organization theory and IS theory. The most fundamental purpose of IVO is to increase a crosspollination between the two theoretical fields. Such a purpose has been presaged in the premises of informing science (see Cohen, 1999), recognized by influential scholars in both fields (e.g., Orlikowski and Barley, 2001), and made the leit motiv in current discussions about the evolution and destiny of the IS field. A better academic crosspollination is expected to raise the value of both fields for practical organizing and managing. In particular, shifting attention to information and IT as the phenomena that are central to organizational politics and culture may have significant implications in the development and performance of real-world organizations. This article introduces infopolitics and infoculture as segments of IVO through definitions, a literature review, and a field study.

The text in the reminder of the article is organized as follows. First, infopolitics is defined and the relevant literature is reviewed. The same is, then, done for infoculture. Subsequently, a case study is presented, which helped to develop the concept of infopolitics and served for pilot testing of both infoculture and infopolitics. Finally, findings of the study are summarized and mapped back into the relevant literature and the IVO perspective, and implications for research are outlined.

\section{Literature Review}

This section discuses the literature that supports our conceptualizing of infopolitics and infoculture. We draw on both the IS theory and organization theory. Direct conceptualizations of infopolitics and infoculture are rare in the literature, and we will have to resort to a creative deconstruction of the tangent texts in order to detect a valuable content. In the case of directly comparable concepts, we will examine them and point out to the usable content and modifications that are necessitated by IVO.

\section{The Concept of Infopolitics}

We define infopolitics in terms of power, agendas, and fights/flights that concern organizational information and IT. Sitting at the nexus of contemporary organizations, information and IT constitute high political stakes. This premise has support in both organizational theory and IS theory. Students of organizations have maintained for long that professional knowledge can be used as a source of power (Crozier, 1964; Mintzberg, 1979; Pfeffer, 1981). By having some special knowledge that others consider a resource, the knowledge holder can influence thought and behavior of others. Feldman and March (1981) suggested that information could support power in even subtler ways. Managers that accumulate periodical reports on their desks implicitly signal their place in organizational hierarchy. Therefore, mere possession of organized data, rather than using it in decision making, may be an aspect of power. Organizational scholars have also addressed technology in conjunction with information and power. While Crozier (1964) associated the power basis with know-how of maintaining manufacturing technology, Barley $(1986,1990)$ shifted attention to know-how of modern IT used for medical purposes. He found that knowledge of using computer tomography and interpreting its output made technicians more powerful than radiologists, who had a power advantage while X-ray technology was in fashion. Beniger (1986) has provided a compelling argument that any IT is a technology of control. His accounts of how the telegraph was used to control railroad traffic can smoothly be extended to today's cellular (mobile) phone, which, in principle, makes the phone owner a subject and object of control, irrespective of space. In all these examples, IT and knowledge of using it contributes to creating a basis of power. The literature on new organizational forms has also touched on power issues in relation to modern IT and information (e.g., Clegg, 1990; Goldman, Nagel, \& Preiss, 1995; Mintzberg, 1979). 
IS theory has also addressed issues of organizational politics. Danziger Dutton, Kling, \& Kraemer (1982) studied consequences of deploying computers in American local government organizations, and published results in a report entitled with "politics." Upon parting from the paper trail, local government organizations from various domains (e.g., financial and personnel administration, police, procurement, courts, and utilities) used computers for record keeping, analysis, and decision making. The authors found that IT supported speed, direction, content and pattern of information flows in such a way that the previously dominant individuals and groups simply reclaimed their positions. Danziger and colleagues termed this outcome "automation of bias," while putting forward their proposition of IT being a "malleable technology" that is capable of serving various interests. This study is important for hinting on what can be considered infopolitical dimensions - the speed, direction, content and pattern of information flows. The notions of control patterns automation and of malleable technology are also helpful.

Zuboff (1984) also identified the phenomenon of reconfirming political positions with new IT and corresponding information management, with the stipulation that power shifts are possible as well. In her highly acclaimed study, which contains "power" in its title, Zuboff (1984) found that there could be two opposite political outcomes from deploying new digital IT in manufacturing and service industries. When adoption of IT coincides with opportunities for organizational change, workers could become empowered and enriched by new skills, and a more meaningful work could result. Zuboff calls this outcome informatization. When change opportunities are lacking, IT coincides with a further deskilling of workers and reconfirming of old power distributions - the outcome termed automation. Zuboff's study is important for pointing to different political agendas coalescing around new IT. In the discussion further below, we will use these examples for conceptualizing agendas of infopolitics. Also, Zuboff's investigation illuminates dialectical aspects of organizational politics related to IT and information. We reflect these aspects in the infopolitical dimensions of fight and flight.

The themes of agendas and fight/flight dialectics in infopolitics apply to the system development process as well. Although working within their specific theoretical frameworks, we believe that a number of researchers have provided useful leads. In particular, various streams within Scandinavian IS research made the theme of political dialectics in the IS development process central to research (see Greenbaum \& Kyng, 1991; Iivari \& Lyytinen, 1999). Orlikowski (1992) also identified agendas and fight/flight behaviors in confrontations between developers of CASE software and management, and Hanseth, Ciborra, \& Braa (2001) detected these phenomena in tensions between corporate units and a strategy of changing organization through an ERP system. Orlikowski (1992) studied ethnographically how CASE software was developed in a large software firm. The software was supposed to improve the productivity in developing IS for the firm's clients. This was done by embedding the firms' IS development methodology in the CASE software, which applied down to specific tasks (e.g., the method of developing user interface). The result of using this software was standardization of work. Orlikowski argues that this can be viewed as an unobtrusive way of controlling the content and coordination in the process of developing IS. However, when system developers felt as being unreasonably constrained by the mandated procedures the CASE software supported, they would resist. For example, they bypassed some functions of the software or even altered them. These findings confirm again that IT is closely associated with power since it can be an extended hand of controlling work consistently with Beniger's (1986) argument. In addition, one can see how system developers fly together in order to fight the imposed organization of work (the IS development methodlogy) and the management behind it. The managers' agreement to enforce the development methodlogy via the CASE software and thus exercise control over the content and speed of work can also be seen in terms of IT-related flight and fight. 
Hanseth and associates (2001) contribute to understanding the same phenomena in relation to ERP systems. These systems typically lead to centralizing information management with paramount political implications: individuals and groups that obtain access to centralized information can enlarge their power basis. Hanseth and associates acknowledge this outcome, while suggesting that the political process may not be straightforward since the centralization force can provoke its counterpart. This indeed happened in the organization the authors studied, Norsk Hydro. This has been a corporation with a global presence that embarked on cross-divisional implementation of an ERP system. The management at the headquarters championed the system, with the goals of achieving a tighter integration and control of the corporation. However, as the project evolved, a number of user groups grew up at dispersed organizational units. In spite of the initial management intention to build one coherent, common system, the implementation process diverged into developing many variants of the system customized to local needs. An implication is that work processes built into the system were not uniformly modeled across organizational units. Another finding is that the system implementation process initially created a momentum for organizational change. Once rolled out, however, the complexity of the system, coupled with maintenance costs, became a hindrance for further changing of organization. From the perspective of infopolitics, centralizing information management is the antecedent to centralizing power. As this case shows, the champion of the ERP system was the upper management, which hoped to seize more power. This is consistent with organization theory: Mintzberg (1979) equated a "strategic apex" of organization with a "pull to centralize." We can add that the centralization pull finds a strong leverage in ERP systems. However, the study also shows that the dispersed organizational units have resisted and managed to keep some autonomy in terms of both system and organizational design. Variations in design of the enterprise system and the thereby induced variation in work procedures were their leverage for saving some political autonomy. This study can help grasp fights in the domain of infopolitics that are triggered by centralizing information.

Computer meditated communication also interacts with organizational politics in various modalities. Groups can evolve around shared interests, using electronic links for self-maintaining exchanges and for advancing their political agendas (Hiltz \& Turoff, 1978; Spears \& Lea, 1994; Sproul \& Kiesler, 1991; Zuboff, 1984). These new political agendas may lead to political fights that result in power changes. A redistribution of power in the CMC context may also come in milder forms, where the intervening factor is argument rather than fight between juxtaposed camps. In an analysis of email communication that transpired within a software development project, Orlikowski and Yates (1994) found that email was used for democratic dialogue, which was occasionally punctuated by balloting acts. As opposed to verbal or paper-based dialogue, electronic dialogue had a capability of chaining the content, thus creating lines of conversation. These led to several ballots. Decisions derived from the ballots were just partially based on the majority vote. Some gave advantage to authority, and so reproduced the old power structure; others favored knowledge, thus favoring knowledge-based power over authority; and yet other decisions were influenced by a sheer persuasiveness of argument, creating even more of a power shift.

Even more tacit political changes can take place in the CMC context when agendas are not clearly articulated and power gains are mapped into the realm of perception. For example, Travica (1999) has found that the usage of IT in American public accounting industry is positively correlated with professionals' perception of a decreased centralization-therefore, a greater professionals' autonomy. Still, the hierarchy was invariant and indifferent of IT usage. Therefore, management control was formally intact, although professionals did not perceive it as such.

Markus's (1983) field study of an accounting system in a chemical company is paradigmatic for many themes of infopolitics discussed above. She studied organizational implications of deploying a Financial Information System (FIS). Design of the FIS and changes in control over accounting information created a battleground between divisional and corporate accountants. The former 
group performed managerial accounting (processing real time information for management and forecasting purposes), while the later group did financial accounting (processing historical information for the purposes of external reporting). Corporate accounting was a new function, placed between corporate management, which it served, and the company's divisions. The corporate accounting function initiated the FIS and defined system requirements on its own. A significant change the FIS introduced was that it redirected the flow of information from the divisional to corporate accountants. Divisional accountants could no longer summarize transactional raw data and send just the summaries to the corporate accountants. The FIS collected all transaction data in a central database, which was under the control of corporate accountants. They could query the data at any time and, on that basis, assess performance of divisions. The FIS also imposed that profit reports, which were in the domain of managerial accounting, had to be based on individual products rather than on aggregate data as used to be the case. Feeling to be at loss, divisional accountants tried to undermine the FIS and fought for saving their old system, which produced aggregate reports. This study suggests that organizational actors stake their agendas on new IS, and compete (fight) for controlling it. Winners gain information-based power, which, in turn, underpins their social power. The study also reinforces the hint on infopolitical aspects that Danziger and colleagues (1982) introduced: the speed, direction, content and pattern of information flows pertaining to a particular IS have to do with power distribution and other political aspects that evolve from this IS.

There have been attempts of categorizing organizational designs in relation to information (Boisot, 1987, 1998; Davenport \& Prusak, 1997). Boisot (1987) derived different designs directly from two properties of information - codification and diffusion. Codification can be understood in terms of a transformation of visceral information into some communication code, formalization, compression, and classification (e.g., highly codified information is patent, while its opposite is tacit knowledge). Diffusion refers to the percentage of a population that a certain piece of information reaches. Ideas of distribution, availability, accessibility, and sharing can help understand diffusion (e.g., information on the Internet is more diffused than patent information). According to Boisot (ibid.), a clan is based on information that is low on codification and high on diffusion within the clan (not in the broader organization in which a clan as a group resides). On the contrary, bureaucracy thrives on information that is both more codified and diffused. Typologies are important for making sense of modalities of infopolitics that may be found in organizations.

In summary, in this section we discussed both IS and organizational literature that is instrumental in understanding our concepts of infopolitics. This literature makes a connection between power on one side, and IT and information (in the broader sense) on the other. The literature also points to different aspects of infopolitics that are of our interest - power, agendas, and fight/flight in behavior and thought concerning information and IT. The discussion will now turn to the literature relevant for understanding infoculture.

\section{Concept of Infoculture}

We define infoculture in terms of stable beliefs (assumptions, values, norms, attitudes) and behaviors (work practices, rituals, social dramas, and communication) that refer to organizational information and IT. Infoculture is the part of organizational culture that evolves around information and IT. Note that our concept of culture includes both the mental and behavioral components, thus reconciling opposed ontologies (cf. Jaques 1952; Schein, 1991). We differentiate between the particular mental artifacts listed above based on the metric of stability-stability decreases from assumption toward attitude (see Hatch, 1997). Work practices refer to accustomed ways of working; rituals refer to acting out of the purpose of reinforcing; social dramas are rituals that 
sentence unacceptable behaviors; and communication behaviors imply communication content, channels, and language.

Taking on the lenses of infoculture, one can easily see that information and IT shape a considerable part of culture in any organization. For example, law firms and banks maintain strict norms aiming at securing the confidentiality of client data, and carry out corresponding work practices and rituals. Innovativeness and production of new knowledge have been raised to a level of cult at organizations like 3M and Microsoft. The Internet, as a rich technological and information context, features in stories explaining the advent of organizations. An example is MediPlan, a large international Internet-based pharmacy in Canada that allegedly was conceived when one of its founders realized that his selling of cheaper anti-smoking drugs to Americans on eBay could be grown into a full-fledged pharmacy business. Thus, norms, values, stories and, other elements of organizational culture that feature various kinds of IT and information are easy to pinpoint in these examples. This is what we mean by infoculture.

The leads to our concept of infoculture can be found in organizational and IS literature. Most of these are tentative, which means that the authors did not have infoculture in mind when they produced their studies. But there are also two cognate conceptualizations. Davenport and Prusak (1997) have defined information culture in terms of "a pattern of behaviors and attitudes that express an organization's orientation toward information" (p. 84). An example of infocultural attitudes is preferences for facts or rumors; examples of infocultural behavior include information sharing and preferences for types of communication channel, such as face-to-face vs. email. The authors distinguish between information culture pertaining to the group and organizational level and information behaviors that are demonstrated at the individual level (e.g., searching for information and using it) (pp. 84, 87). Bressand and Distler (1995) have used a concept of "infoculture" in the context of social networks. According to these authors, infoculture contains: "shared objectives and mutual expectations" that make a basis on which network members can agree on joint projects and mobilization of network resources; "rules that govern changes of rules;" and "the background knowledge" that actors take for granted and enact in their daily use of the network (cited in Ciborra, 1996, p. 122). Both these concepts are valuable for our conceptualizing of infoculture. However, we expand Davenport and Prusak's concept to include IT, and we avoid the ambiguity of the generalist cultural approach in Bressand and Distler's concept by focusing clearly on information and IT.

Deal and Kennedy (1999), prominent researchers of organizational culture, have provided a remarkable argument about the impact of computers on contemporary organizational cultures. While the authors give some credit to computers, their real focus is on what they believe are undesirable consequences of intensive use of this technology: "pluses are offset by diminished social interaction with one's peers and a sterile interface with a computer rather than a supervisor" (Deal \& Kennedy, 1999, p. 148). For instance, rituals that used to be social are now machinetimed and dictated; face-to-face communication is more often than not replaced by impersonal electronic exchange; and old organizational cultures that fed on personal contact are replaced by new cultures of "computer-mediated life that distances people and finds heroes in the whiz kids who can fix software glitches or the computer system itself." The problem with computers, assert the actors, is that they are rarely used for reinforcing core cultural messages. Instead, computers have created new cultures of isolation and contributed to modern corporate maladies beside other causes, such as shareholder value and outsourcing. The interesting phenomenon Deal and Kennedy point to is that the primary effect of computers is to distance people. The literature on computer mediated communication lends some support to this claim. While the authors' interpretation of the distancing effect is value-laden, it corroborates our proposition that electronic IT has become a central cultural phenomenon in organizations. 
Orlikowski and Gash (1994) used the term "technological frames" to refer to the way organization members make sense of and assign meaning to organizational artifacts and to assumptions, knowledge, and expectations expressed symbolically through language, visual images, metaphors and stories (p. 176). The authors studied an organization that was implementing groupware on a large scale. They identified two different sets or values and assumptions in this organization. One characterized the IS department (technologists) and the other pertained to the business core of the organization (users). The technologists maintained the values that praised technical indicators of work, believed that the new IT could change the firm, and assumed the users were typically ignorant about IT and that "they would come if the system was built." In contrast, the users valued business criteria of performance (e.g., hourly charging rate was the main unit of measurement), and could not associate the new IT with performance requirements. Information rather than IT was the key in their view, and it had to be accurate, secure and of a certain quality. Apparently, this study provides evidence on infoculture in the form of assumptions and values related to organizational IT and information. Another contribution to our concept of infoculture is in putting forward the postmodernist assumption that organizational culture can be fragmented (Kunda, 1992; Martin, 1992).

Another pointer to the phenomenon of infoculture is in Orlikowski's (1996) study of a software company's help desk, which used new database and communication systems. From the IVO perspective, the most interesting finding is that a whole corpus of new cultural artifacts had emerged in this organizational unit. For example, a value of good documenting of the problem solving process had surfaced. Then, the grapevine began relaying a dramatic story, which portrayed a frustrated user of the problem solving documentation that experienced a shock realizing that he was the author of the poor document. This story apparently reinforced the value of doing the documenting job well. A new norm prescribed the language used for documenting purposes: it had to be "professional and diplomatic." A part of new cultural legitimacy was that the authorship was considered to be a seal of quality. This norm implied that professional should strive to have their names dissociated from a poor documenting work and strive to become heroes of documenting. This logic brought the new culture reasoning to square one--"do document well!" Obviously, all these cultural innovations coincided with new IS. What may be less apparent is that they all referenced a common larger assumption: new knowledge created through solving customers' problems had to be preserved as a valuable resource. Therefore, we can see that information and IT are the source and sink of these innovations, and this fact gives them the character of infoculture. This study also suggests that infocultural changes may occur opportunistically rather than intentionally.

As in the case of infopolitics, ERP systems could be turbines of infoculture changes as well. Sarker and Lee (2000) found that the organization they studied had to change its "dysfunctional culture" in the course of implementing a large-scale enterprise system. Before the implementation, a culture set in characterized by "a sea of paperwork," a lack of trust, inefficient processes, and inadequate technological infrastructure (p. 419). Departments tolerated ambiguity surrounding the status of orders, and production and engineering departments could not get in agreement about scheduling. The former would routinely set production deadlines without asking the latter, and the latter would routinely resist. This culture of ambiguity and dysfunctional scheduling was attacked in preparations for the ERP system. Leadership, open communication, and an effective implementation team interacted in the process that led to success. Finally, practices of more open inter-departmental communication emerged along with coordinated scheduling as artifacts of a revamped organizational culture. Since infoculture is the part of organizational culture that evolves around IT and information, the important implication of this study is that ERP systems can trigger a radical transformation of infoculture. In addition, the study has outlined several characteristics that can be considered dimensions of infoculture - the proportion of paperwork vs. 
digital processing, the match between technological infrastructure and process efficiency needs, and properties of inter-departmental communication and coordination.

In summary, this section defined infoculture and discussed relevant organizational and IS literature. This literature has provided evidence and theorizing on various cultural artifacts that have to do with information and IT - assumptions, values, norms, stories, work practices, and rituals. Links between these and our conceptualization of infoculture have been outlined.

\section{Methodology}

Our empirical investigation of infopolitics and infoculture used the research design of case study (Hunter, 2004; Lee, 1989; Yin, 2003). It was a single organization longitudinal study, spread over 25 months (summer 2001-fall 2003). The organization investigated was a venue of large festival in Canada code-named the Folklandia Pavilion (or just the Pavilion), which has exhibited characteristics of a voluntary establishment and small businesses. Epistemologically, the study belongs to the interpretivist inquiry, which is meeting an increasing acceptance in the IS field (Baskerville \& Myers, 2004; Klein \& Myers, 1999). Most of the works cited in the literature review above belong to this inquiry (Deal \& Kennedy, 1999; Hanseth et al., 2001; Markus, 1983; Orlikowski, 1992, 1996; Orlikowski \& Gash 1994; Orlikowski \& Yates, 1994; Sarker \& Lee, 2000; Zuboff, 1984).

\section{Data Collection}

For collecting data, a triangulated methodology was used that consisted of ethnography, interviewing, and document analysis. The ethnographic method drew on prolonged field observation and participation in activities and events in the organization studied. Ethnographic method originated in anthropology and have been used to a limited extent in IS research (e.g., Orlikowski, 1992; Suchman, 1987). The contemporary use of ethnography has somewhat deviated from the traditional model in which the researcher was supposed to be a neutral observer. Instead, the researcher is allowed to let his/her hidden self surface through action in the field and the cognitive makeup s/he brings into research - knowledge, beliefs, philosophical orientations, and emotions (Tedlock, 2000). The rationale is that social science deals with phenomena that are intersubjective in character, and, therefore, the researcher becomes yet another subject involved in the social context that learns not only by observing but also by interacting with others (Tedlock, 2000: 471; see also Baskerville \& Myers, 2004, p. 332). The ethnographic method deployed in the present study enabled the researcher to have ready access to dozens of organizational members and experience actual organizational life. This data collection resulted in a journal, which contained observations, communications, and research design details (questions and hypotheses for research, incrementally developing findings, ideas for coding, etc.).

Interviewing was another method of data collection. The interview transcripts contain 82 entries related to the subjects interviewed - organizational members and external actors. Interviewing was performed in various modalities - from a short/structured to longer/semi-structured one. The third data collection method was document analysis. It was applied to various records on the organization's activities, meetings, finances, and performance. Furthermore, a database was developed in the course of study in an effort to create a chain of evidence linking the research question with methods, data, and this final report (Yin, 2003). The database contains paper and electronic documents on the preparations of the Pavilion and its operations during the festival days, archival documents, interview data, the journal, media clippings, coding schemes, tabulations of the categories coded, spreadsheets with financial data and calculations, email folders of certain organizational members for 2002 and 2003, and some other auxiliary information. 
The case study intended to answer the following research question: What are the aspects of infopolitics and infoculture in the organization under study, and how do they relate to other organizational aspects and organizational performance? In accord with interpretivist field research, this research question was shaped in the course of the study (more discussion below).

The case data were analyzed in the course of study as well as after finishing the field investigation. During investigation, data analysis relied on the iterative process discussed below (see Figure 1). In a nutshell, once a focal construct of observation, interviewing, and document analysis was defined (e.g., a particular ritual of infoculture), a working hypothesis would be set and search for data followed. The definition of the construct was used to derive keywords to be used as a "sifter" for coding the data: Identified instances of a construct would be saved in the appropriate rubric, and potential useful data would be marked for a revisit in the future. Electronic tools assisted the process. More often than not, it happened that a single process would not end up with a finding as the researcher's attention was called to some emergent event or because relevant data were missing. The coding of all the data was revisited and finalized after the field investigation was closed. Another method used both during the investigation and afterwards was to have external readers comment on draft findings. These readers were some of the key organizational actors, and the drafts were write-ups of findings that would jell up in the process of research.

\section{Process of Interpretivist Inquiry}

The initial intention was just to learn about the internal organization and information practices and technologies in the Folklandia Pavilion. Then, as the study progressed, attention was focused on issues of infoculture. A trigger for the shift came at the very start, although it did not shape the research question right away. The person responsible for getting the researcher into the organization (the Informant) provided a stark commentary on difficulties experienced in preparations of the Pavilion for a new Festival year:

Ifeel as if we have to discover the hole on the flowerpot every year anew. Every time we start the preparations, we have to go through pains of shaking up our memories, wondering what we did the last year, how we did it, what happened, why we didn't do things differently... We learn and then we forget. Not very smart, eh?

The commentary above clearly indicated a possibility that knowledge management or records keeping methods were causing the trouble. A metaphor of "organizational amnesia" imposed itself as the guide at that point of investigation. We hypothesized that work manuals could have been deficient or inaccessible; documentation on problem solving could have been poor, as dramatically happened in Orlikowski's (1996) case. If access to information was a problem, some IT-related aspects could have been responsible (design issues, availability of IT, impact of IT on organization of data). The interesting fact was that nobody could tell us anything useful for explaining the "organizational amnesia." The people would just shrug their shoulders, or occasionally utter: "That's how the things have always been around here." We thought that tradition could have been a vague, general cause of "organizational amnesia," and if so, information and IT problems were related to it. Invoking the concept of infoculture became a sensible option at that point, and "infoculture" was brought into the research question. Then, we learned that the organization was low tech, primarily based on paper trail. We concentrated on accessing the organization's memory - the documentation on work procedures and problem solving, and paper records that tracked financial aspects.

Attempts to access organizational memory brought us, for the first time, before a wall. Part of the organizational members knew nothing about this and believed that only a certain "privileged group" had a hold of the information in question. This "privileged group" consisted of seasoned volunteers that participated in the Folk Festival for many years. Some of the group members were 
buttoned up; others were kinder and promised help in accessing the requested information; and yet others asserted that all work manuals they ever needed were "in their heads." It took about four months to establish that a division between the "privileged group" and others really existed. This preliminary finding suggested that part of challenges the Pavilion was facing had to do with organizational politics. Therefore, organizational politics became part of the research question. At that time, the IVO framework still did not operate with the concept of infopolitics. As the study progressed, the idea gradually crystallized that information politics may be a sensible aspect to add to IVO. However, no direct literature supported this idea. As our filed data were telling more of the story, the initial idea on infopolitics became more pronounced and analytical. Eventually, the study informed the IVO framework with the elaborate concept of infopolitics.

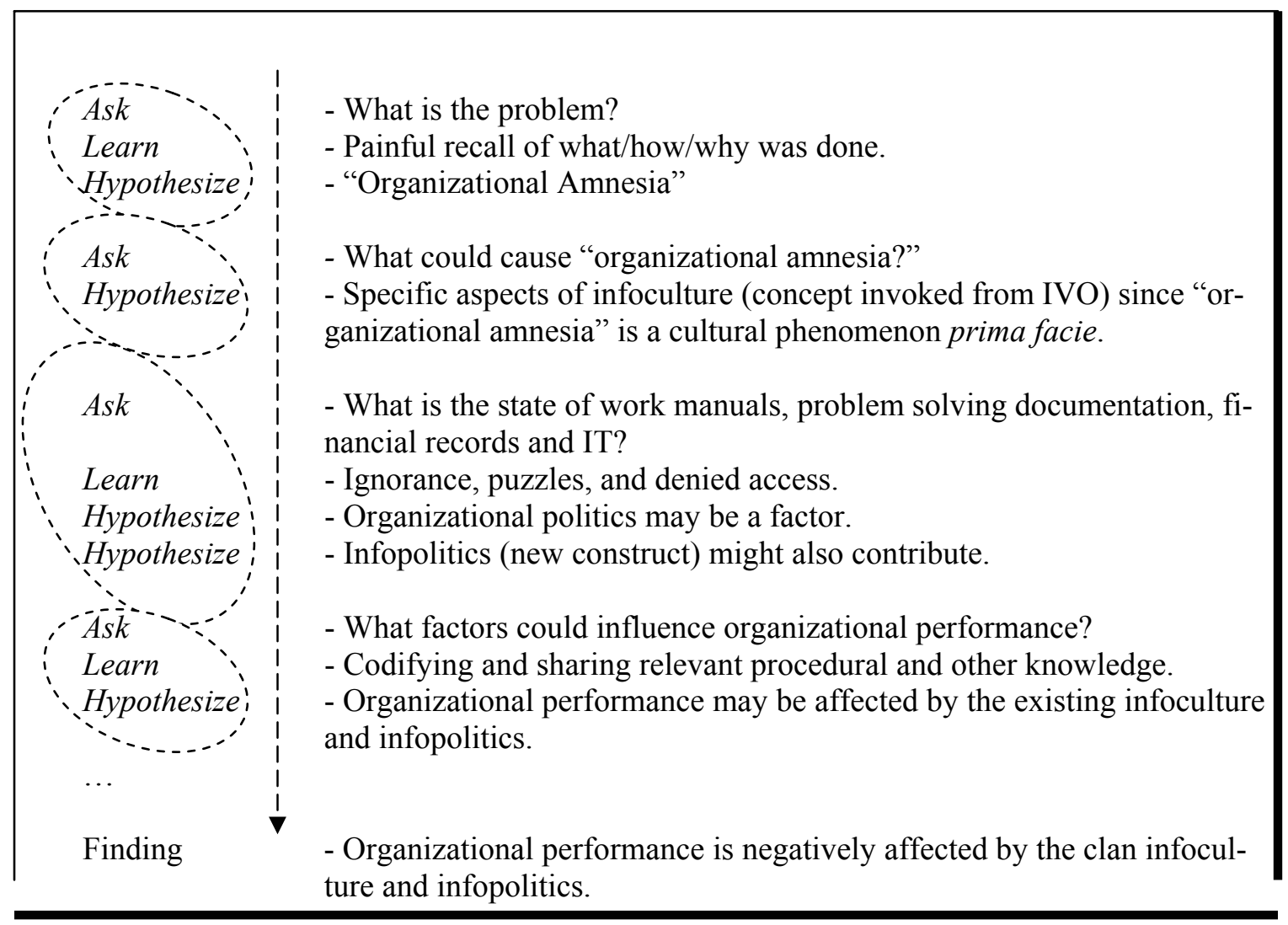

\section{Figure 1: The Process of Interpretivist Inquiry}

The last part of the study's research question asks about relationships of infoculture and infopolitics with other organizational aspects and organizational performance. This part was formulated at about the end of the first year of investigation. While the effort was concentrated on discovering causes of "organizational amnesia," the researcher also learned that the financial performance of the Folklandia Pavilion had usually been sub-optimal in comparison to similar pavilions participating at the Folks Festival. This elicited the idea to expand the investigation toward the relationship between organizational performance and infoculture and infopolitics. The convenience of being in the field of study helped learn about subtle financial "loopholes." For example, the food was prepared so that recipes used varied over years and across different cooks within a particular year. This led to hypothesizing: if the Kitchen function had not retained the knowledge of a right proportion of ingredients that guaranteed both food quality and cost-effectiveness, losses could accrue due to smaller sales and higher costs. As opposed to a restaurant business for which 
the retention of optimized recipes would be a trivial routine of knowledge management, the Kitchen in the Folklandia Pavilion provided a different picture. Old-fashioned house wives who prepared esoteric dishes mainly staffed this unit. Many of them owned some culinary trick and used it to give a unique twist to their dishes. Therefore, both the varying quantities of food ingredients and the "tricks" could have been money drains. Based on these insights, the performance aspect was added to the research question.

The way of completing the research question reflects the process of the interpretivist inquiry used in this study. The process was iterative and spiraling, and it consisted of three steps - ask, learn, and hypothesize, as shown in Figure 1. The Ask step implied a specific question for investigation; Learning translated into collecting data; and Hypothesizing meant creating plausible answers to be investigated further (asked and learned about). These steps were repeated (not necessarily all of them every time), thus forming loops, and one loop would lead to another, as shown in Figure 1. A certain finding - more often than not, a preliminary or draft finding rather than a final onewould crown the process. Figure 1 depicts the logic of applying the inquiry process to the research question before radical organizational changes happened in the Pavilion. Once these changes happened, the looping logic of field study led us to reevaluate past data and draft findings. Some aspects of the previous organization became clearer only through this flashback.

Note that the process of interpretivist inquiry was applied to other specific ("smaller") questions of the research agenda as well. This agenda was naturally evolving in the course of investigation. One may picture these specific questions as research tasks running in parallel or a sequence and resembling a Gantt chart. But the analogy stops with the image of task bars, since it was not possible to define much ahead specific questions for investigation, their relationships and (especially not) their time aspects. The questions would be emerging from field observation, and then worked out as the circumstances allowed. Moreover, perhaps half of the time the researcher would just resort to "being in the field" - observing with or without participation without having a clear idea what to look at/for. Sometimes this would provide evidence for a phenomenon that was not meant to be attended to at that particular point in time. This resembled a phenomenon of information encountering (Erdelez, in press), which can be understood in terms of spontaneous learning and felicitous insights. One such example is the episode from final preparations of the Pavilion in 2001, which is described below.

\section{Findings}

In this section, the organization under study will be described, and an evolutionary trajectory of the Folklandia Pavilion's infopolitics, infoculture and organization will be discussed.

\section{Folklandia Pavilion}

Folklandia Pavilion is a venue of a large festival (Folks Fest, the Festival) that has taken place in Canada since 1972 during two August weeks. The festival is organized by a non-profit organization (the Festival Agency), which is allowed to carry a surplus income into a new fiscal year. The Festival agency provides marketing, instruction, logistical support, and other services for the Folks Fest. The festival program is designed and carried out by communities with different ethnic backgrounds residing in the Festival city. They get a chance to represent their cultural background and make some income for funding their activities. Each community participating at the Festival presents its offerings in a venue called pavilion. There have been 40 to 50 of them in recent years, attracting about 300,000 visitors from Canada and the United States. Each pavilion is active for one week in August. Pavilions are backed by a sponsoring organization that provides financial and legal guarantees (e.g., a cultural association of an ethnic community). Other stakeholders include the travel industry of the province, hotels, grocery chains, the province's beverage distributor (a government-run corporation), and owners of buildings that are rented by pavilions. 
A pavilion must, as a minimum, have a hall for visitors that includes a space for artistic performances. Additional facilities include a bar for selling beverages, kitchen, food storage, and room for demonstrating traditional crafts, selling merchandise, and entertaining children. In a standard model, a folk dancing program is presented on the stage, while guests eat and drink "goodies" purchased on the spot. Thus, pavilions generate income by selling tickets, food, beverages, and merchandise (e.g., memorabilia, folks clothing and shoes, jewelry, packaged food, and music products). Pavilions withhold all the income but the money from ticket sales, which they have to split with the Festival Agency. In recent years, there has been a trend of increasing net income both on the pavilion and Festival Agency side. These financial aspects, along with the freedom of designing the artistic program and attracting visitors in creative ways, give the pavilion characteristics of a small business. On the other hand, a pavilion is also a non-profit voluntary organization, relying mainly on the goodwill of its staff.

A special challenge in organizing and managing a pavilion is how to keep a certain level of volunteer activity over months preceding the Festival in order to act as a fully effective professional organization for one week in August. Since there is no pressure of work obligations, no clear bottom line, and no formal reward system, the level of activity of volunteers is irregular rather than steady. However, planning, money raising, staffing, scheduling, training, and procuring, as well as operational preparations (e.g., cooking the food that can be frozen) must run continuously. Then, pavilions' staff and the volume of operations start "swelling" in weeks preceding the Festival. Operations reach a climax during Festival days. At that time, support of the Festival Agency may be vital. Indeed, the Agency does function 24/7 in that period, resembling the commandant headquarters in a major military battle. The Folklandia Pavilion was struggling for years to recruit sufficient numbers of volunteers in the preparation period. During the Festival, it would engage between 50-150 volunteers.

Another challenge the pavilions have faced refers to organizing and managing. According to recommendations of the Festival Agency, a pavilion is supposed to be organized as a functional hierarchy. At the top of it sits the coordinator. This person assumes the role of a universal manager, being responsible for all aspects of pavilion activities, from the strategic to the operational level. Responsibilities include financial liability before health and other inspections. Coordinators' immediate coworkers are supposed to be the heads of various pavilion functions. These people should are supposed to develop an effective organization that is able to perform smoothly during the Festival under a pressure that hardly has equivalents in small business. For example, there can be 3-5 shows a day, 50-800 visitors per show (depending on the seating capacity); hundreds of meals have to be served; stage performances (usually carried by amateurs) should be at a certain artistic level and with precise timing; safety of facilities must be continually kept; security among the crowd that can liberally consume alcohol must be maintained; and so on. People who typically are not professionals in areas they cover carry all this out. These people change over time, and can drift away unexpectedly in critical moments. Given all these conditions, it is not surprising that the principle of formal authority does not apply well to this context. The corollary is that power may have various sources, including personal prestige, tradition, and ad hoc deals. In contrast to these obstacles, both the volatile character of organizational membership and the fluidity of power models imprint certain flexibility on the organization of pavilions. In principle, different organizational members can shape the organization in different ways.

\section{Clan Era}

In 2001 entirely and to a significant extent in 2002, the organization, strategic aspects, operations and most of the management of the Pavilion were in hands of a group of volunteers that had a longer tenure with the Pavilion - the insiders (see Figure 2). We call this the era of clan organization. The insiders consisted of a family (mother, father, and son) sitting at the power center ("the 
core family") and its immediate coworkers ("associates"), both recruited from the ethnic community behind the Pavilion. The core family used to run the Pavilion as a family business: the mother led the Kitchen function, the father controlled finances, and the son usually performed as the Pavilion coordinator and media person, in addition to shaping and performing in the artistic program. As one volunteer commented wittingly:

That family holds everything that matters in their hands. They have all the might. Just the Holy Ghost is missing. Oh, and don't be mistaken-the mother comes first."

Organizational structure of the Pavilion resembled a simple form that can be identified in small entrepreneurial organizations, such as mom and pop's business (Mintzberg, 1979). This is an undifferentiated organization in which members perform multiple roles, turfs shift and overlap, and lines of reporting as well as many other relationships are not formalized. Personal influence, agreement and improvisation compensate for the lack of formal rules and regulations. The Folklandia Pavilion fit this model. We also borrow from the concepts of clan organization (Ouchi, 1979,1980 ) and power organization (Handy, 1993) in order to describe this organization. The organization of Folklandia Pavilion had a powerful agent at its center- "a spider," in Handy's (ibid.) terms. In our case, this was the core family (see Figure 2). The spider controlled the web, influencing thought and action of other inhabitants. Next to the center is the circle of associates. The core family and associates resembled a clan. Other organization members - the volunteersinhabited the outer, marginal circle of the organization. Therefore, the term clan organization here refers to the clan (insiders) embedded in the broader organization, rather than to the organization of a clan as a special, closed group. The insiders planned, controlled and performed some operational work, while the outsiders did only the operational work under supervision of the insiders.

\section{Infopolitics}

The concept of infopolitics implies that the power of organization members and groups springs from controlling organizational information and IT, thereby making information/IT have-nots dependent for the information and IT resources. In the Folklandia Pavilion, information/IT-based

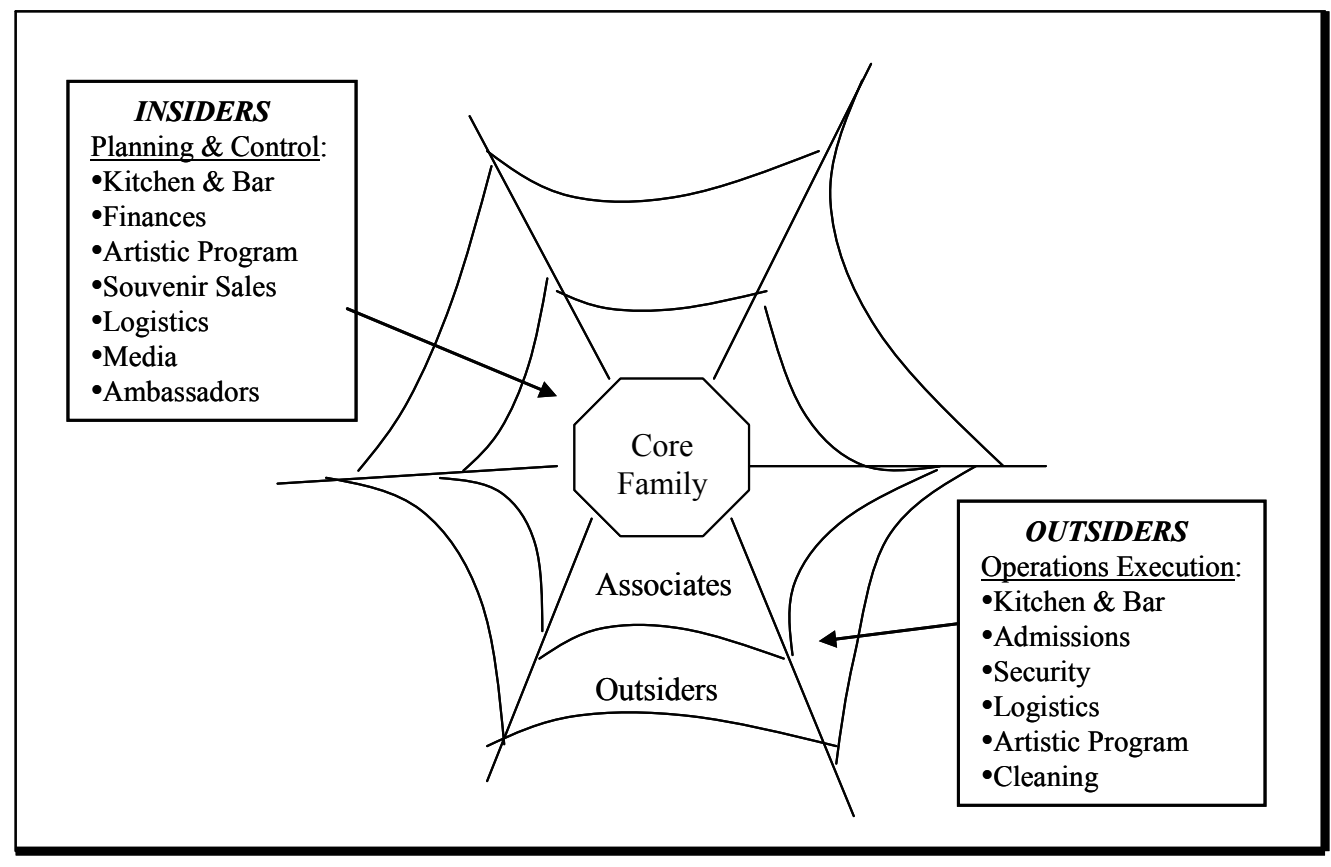

Figure 2: Organization of Folklandia Pavilion in Phase I 
power was concentrated in the hands of the insiders - firmly in 2001 and for the most part in 2002. This painted a specific infopolitics, the characteristics of which are explained below.

Running organization with eyes closed: information power. Knowledge was the specific form of information that gave power to the insiders. This was the knowledge of the Pavilion's organization, operations and management, as well as its past, and this knowledge was monopolized (see Table 1). The insiders excluded others from important Pavilion's business in order to protect their knowledge and, therefore, their power basis. Outsiders were included in rather marginal activities and were not invited to participate in decision making activities. Outsiders were asked if they had access to work manuals or simple descriptions of the Pavilion's procedures, hygienic and technical standards that needed to be met, and other items on the operational side. Typically, they were not aware of such documentation or they thought that it did not exist. The insiders who were approached with the same question either promised to help access such documentation or denied a need for it. As a seasoned insider put it:

There are no manuals simply because we have been part of this Festival for many years, and we have learned all we need to know and kept it in here [the person pointed to his head]. We know it, and we do it. We can run this Pavilion even with our eyes closed.

There was truth in the claim about familiarity with the operations management and execution. The familiar space (although in many respects unsuitable for hosting approximately 100 visitors per show as it usually had), the familiar type of audience, and accustomed methods of improvising material resources and procedures helped the insiders' self-confidence. However, it was also true that this organizing and management competence was confined within the Pavilion's boundaries. Communication and relationships with the Festival Agency, other pavilions, media, and various other players in the government and business environment constituted a terra incognita. Only coordinators would deal with these issues as they would, and many insiders seemed to believe that these external tasks were marginal. As a consequence, the Pavilion's standing vis a vis other pavilions was never objectively assessed. These limited and random exchanges with the environment had brought this organization more toward a closed system model.

Customized KISS: information agenda. If the insiders could run the pavilion with closed eyes, it could have been because their political agenda had long been unchallenged. Organizational politics includes goals based on self-interest or an agenda, and following this axiom, we developed and tested a concept of infopolitical agenda through interplay of theory and field experience. However, direct leads to such a concept missed in the literature, and so we had to apply different reading in order to obtain some theoretical footing; see above for the discussion on contributions of Markus (1983), Orlikowski (1992), and Zuboff (1984). In these studies, opposed political camps were defined by their different ideas and intentions regarding information content, flows and uses, systems design and uses, and so on. Different agendas competed in the cognitive domain as well as in action. We learned in the course of our field investigation that different agendas drew importantly on information and IT and, therefore, could be considered infopolitical agendas.

The core of the infopolitical agenda of the insiders was to preserve the status quo in the distribution of knowledge. This ensured a general status quo. This finding was a result of a longer looping process rippled with uncertainty. Uncovering infopolitical agendas is a demanding research task. As political factions group and maneuver in order to protect/seize their territory, they advance their agendas in a zigzag manner, playing along a continuum whose ends are obscurity and clarity. Sometimes, a political faction may push for its agenda without trying to conceal it. At other times, the faction can act in a manner that obscures its real goals behind smoke screen declarations and confusing messages in order to mislead opponents and attract bystanders. This ambiguous character of political behavior challenges the researcher's ability to recognize true agen- 
das. In the process of investigation, one needs to develop an analytical model, a set of testable criteria to be used as a litmus powder for detecting agendas of infopolitics. The litmus powder for testing if the insiders' agenda was to preserve a monopoly of knowledge was a question or proposal of organizational change. We attended to interactions between the outsiders and insiders in which the former would propose some new methods at the operational or strategic level. Examples include the methods of food selection, production and preservation, organizing the souvenirs booth, designing the artistic program, and introducing computers for tracking operations and expenditures. New ideas were typically turned down or ignored. We also used the litmus test on the insiders by asking whether they had thought of doing certain things in different ways. The responses were negative and, at times, bitter. As the litmus powder turns to red in an acid solution, so would the insiders' faces turn red upon facing change-provoking questions. A number of the respondents justified their choice by arguing that there was no need to "complicate things." As if they wanted to convey the KISS motto used in the context of systems development: "Keep It Simple, Stupid."

\section{Table 1: Trajectory of Infopolitics in Folklandia Pavilion}

\begin{tabular}{l|l|l|}
$\begin{array}{l}\text { Infopolitics } \\
\text { Component }\end{array}$ & \multicolumn{1}{c|}{ Clan Era (2001/2) } & \multicolumn{1}{c|}{ Teams Era (2003) } \\
\hline Power & $\begin{array}{l}\text { Insiders' monopolize knowledge on } \\
\text { organizing the Pavilion and informa- } \\
\text { tion on past performance as the basis } \\
\text { of power. Outsiders show signs of } \\
\text { resistance. }\end{array}$ & $\begin{array}{l}\text { - Insiders' knowledge monopoly obliter- } \\
\text { ated as outsiders acquired old and new } \\
\text { knowledge. Knowledge sharing } \\
\text { within/between teams. } \\
\text { - Knowledge of modern information } \\
\text { management and computers used as the } \\
\text { power basis. }\end{array}$ \\
\hline Agendas & $\begin{array}{l}\text { Insiders' interest is to preserve the } \\
\text { status quo in the diffusion of infor- } \\
\text { mation and use of IT-outsiders' in- } \\
\text { terest is to overturn it. }\end{array}$ & $\begin{array}{l}\text { - Outsiders push for overall modernizing } \\
\text { of the Pavilion's information and particu- } \\
\text { larly IT. Information diffusion increased. }\end{array}$ \\
\hline $\begin{array}{l}\text { Fight/Flight } \\
\text { (Behaviors, } \\
\text { meanings })\end{array}$ & $\begin{array}{l}\text { - Insiders block outsiders' attempts at } \\
\text { more systematic information and } \\
\text { knowledge management. }\end{array}$ & $\begin{array}{l}\text { - Principles of more systematic informa- } \\
\text { tion and knowledge management win. } \\
\text { - Open communication channels and }\end{array}$ \\
& $\begin{array}{l}\text { - Ilosed loop communication. } \\
\text { - Insiders deny computer-outsiders } \\
\text { embrace it. }\end{array}$ & $\begin{array}{l}\text { team spirit prevail. } \\
\text { - Flight around computer use bring many } \\
\text { Pavilion members together. }\end{array}$ \\
\cline { 2 - 4 } & $\begin{array}{l}\text { Vested vision of Pavilion equals a } \\
\text { homey, affordable dinning place. }\end{array}$ & $\begin{array}{l}\text { Vested vision of Pavilion equals a com- } \\
\text { petitive economic enterprise. }\end{array}$ \\
\hline
\end{tabular}

We applied the litmus test to the outsiders as well by simply modifying the test question; for example, "There seems to be no alternative to the way this has been/can be done, is there?" Some outsiders would "turn red" upon facing this questions. But others would be rather indolent. They were unsure, or simply did not know better and went along with the stream.

The insiders saw danger in any sort of change. New methods would imply new skills and competence that could obfuscate old skills and experience of the insiders. Staying on the familiar ground was not only easier, but it was also the key to preserving the insider group's identity, cohesion, and turf. Since they monopolized operational and strategic knowledge, others depended on them in a substantial way, regardless of the capabilities they could have had. 
The outsiders were entirely subdued in 2001. In 2002, they started raising heads in 2002, with changes in the Pavilion's leadership. On the initiative of the Pavilion's sponsoring organization, a new coordinator outside of the insiders circle was appointed. Another key position, the treasurer, was also filled with an outsider. These two and the Informant (mentioned above), who was in charge of purchasing operations and pavilion setup/tear down, formed the core of an emerging new leadership. Although the clan organization was perpetuated in 2002, some improvements in information management and financial discipline were achieved. Change and innovation became big goals on the political agenda of the new leadership and the volunteers they influenced. But they faced a two-tier firewall: change was usually blocked, and access to existing knowledge was barred. In months preceding the Festival in 2002, the emerging new leadership had to endure through a painful acquisition of a basic Pavilion's how-to-do. The insiders would rarely be willing to share their experience, and the members of the emerging leadership had to beg, cajole, and bargain for information. An aggravating factor was a lack of written procedures and written records that, in general, characterized the infoculture of the Pavilion (more discussion in the section below). As the preparations of the Pavilion intensified before the opening day, withholding the knowledge produced even more dramatic consequences. This will be illustrated with an episode.

On the opening day of Folks Fest 2002, there were many problems with the electrical installation. Suddenly loaded with many cooking and warming devices, sections of the installation would often go down. The breakers went off, some electrical outlets burnt out, and nobody knew precisely what could be plugged in what outlet. After hours of going through a stressful trial and error process, the insiders, helped by outsiders, established a functional system. The Pavilion hall ended up in a maze of extension cords and wires with cooking and warming devices scattered around it. The setup and trouble-shooting operation was accompanied by a continuous and, at times, heated discussion on how "things worked last year." Then, three hours before opening the Pavilion gate, the device for warming food was plugged in. It knocked down the entire electrical system. The device was homemade by an insider who was a self-taught electrician (the Technician, a long-term insider). To the dismay of the volunteers present, nothing could be done to bring the system up. The Technician eventually arrived. He determined what was incorrect in the system setup, did some re-plugging, reset the warming device, and the Pavilion was ready to head for the grand opening. Some volunteers confronted the Technician on the spot. They asked if it would be wise to create a schema of a functional electrical setup and save it for the future use. The Technician resisted:

If I draw that schema, it would be a too complex drawing. Nobody could read it, and so I'd again have to be around to help. And I am always around anyway... So, why need a schema?

It appeared that the insiders who witnessed this conversation shared the Technician's seemingly infallible logic. Nobody argued, no comment was uttered. Instead, consent was expressed via head nodding, shoulder shrugging, or hand waving. The KISS axiom could have convinced the Technician that his mind was the best place for storing the design of the electrical installation. But this episode and its protagonists may also convey a deeper meaning related to a tendency of keeping things intact. Hence, the KISS axiom can be customized to this situation to read-"Keep It Same, Stupid!"

"Family gathering" in the "underground:" clash of vested visions. The process of solidifying an infopolitical agenda requires congruence in group perception and thinking. The group members join in a flight, united around shared meaning and thought. The more exclusive their flight is, the deeper they can draw a confrontation line between themselves and others. Internal flight triggers external fight. Small group theory can guide us in understanding these phenomena (Janis, 1982; Lewin, 1948). We have used it coupled with theorizing on the clan organization (Boisot, 1987; Ouchi, 1979, 1980) in order to explore fights and flights in the realm of infopolitics of the 
Folklandia Pavilion. We learned that flights and fights in the information domain could be categorized as cognitive and behavioral (Table 1). In our case, there happened a clash of disparate visions of what the Pavilion was supposed to be. We term these opinions "vested vision" in order to emphasize the political background of this fights and flights.

To the chagrin of the insiders, the emerging new leadership questioned the entrenched vision of the Pavilion. New recruits were traditionally taught that the Pavilion was "a family gathering" and "a hospitable place," and that the goal was to attract the community members and immediate neighbors by "a homey atmosphere and a good, affordable dinner." In contrast, the emerging leadership framed these images rather pejoratively. They often used the term "underground" to refer to the Pavilion. "Underground" was a complex metaphor that was supposed to convey rich meaning rather than the simple fact that the Pavilion was located in a basement. Instances of using the term "underground" we coded include "a lack of fresh thinking," "non-ambitious business," "fledgling enterprise," "dull place," "a tight ship," and "a falling apart place." The image of a homey affordable dining place was countered by the catch phrase "lackluster workmen's cantina." The outsiders countered the insiders' vested vision in a constructive way, as well. They argued that the Pavilion was supposed to be "an economic enterprise." They wanted to move the volunteers to "think big and bold" and to compete with successful Pavilions. To this end, a number of organizational and management changes were initiated in 2002. For example, a fund raising function was established, planning, scheduling and other preparations started months ahead of time, and elements of teamwork were introduced. In spite of all these efforts, the overall clan character of the organization remained resilient.

Loosening vs. tightening: fight in action. In 2001, the reign of insiders was largely unchallenged. Confrontations started in 2002, when the emerging new leadership pushed for gaining information power, clean records keeping, and a more systematic management of information. The newly recruited treasurer was part of the leadership, and fought persistently for these changes. However, as if they followed the modified KISS axiom above, the insiders resisted by sabotaging new procedures of planning publicly important expenses and of submitting timely receipts to the Treasurer. They also tended to keep communication closed in their loop, ignoring the emerging new leadership. Consistently, oral informal communication was their favorite channel (more discussion in the section on infoculture). When the aversion toward recording knowledge is entered, the picture of the mainstream infopolitics exhibits a looser approach to information and knowledge management, with a very limited role for modern IT. In contrast, the emerging, marginal infopolitics was nurturing a more methodical approach to information and knowledge management, where modern IT played an important role.

The relationship toward IT indeed created a whole battlefield in its own right. A number of members of the emerging new leadership had intermediate or higher computer skills. They insisted on creating accurate electronic information and saving it for current and future uses. The insiders blatantly ignored this technological push, meeting it with either a wall of silence or overt denial (see more on this in the next section). The main tendency of the insiders to bring in more order and tighten the loose information procedures and flows was, therefore, effectively blocked.

In summary, in 2001 entirely and to a significant extent in 2002, the organization, strategic aspects, operations and most of the management of the Pavilion were in hands of a group of volunteers that had a longer tenure with the Pavilion - the insiders. Other organizational members were outsiders who had little say in Pavilion's affairs. The organization fit a simple form design (Mintzberg, 1979), the clan organization (Ouchi, 1979, 1980), and power organization (Handy, 1993). The infopolitics was characterized by insiders' monopoly of knowledge, localized diffusion of other forms of information, irregular management of information and knowledge, closed loop communication, computer denial, and a vested vision of the Folklandia Pavilion being a 
homey dining place. In 2002, this infopolitics exhibited cracks when the emerging new leadership began challenging it.

\section{Infoculture}

If the concentration of power was the landmark of the clan organization, organizational theory suggests that a complementary culture had to be in place with an equally important role. According to Ouchi (1980), organizational culture is essential to the genesis and maintenance of the clan organization. This organization thrives on a strong culture that is achieved through a strict indoctrination. The beliefs clan organization members faithfully share enable the organization to function and deliver, thus doing what formal rules do for bureaucracy and what performance indicators do for the market organization. Handy's (1993) ideas about the his power organization design resembling a spider's web also illuminate the cultural milieu of the clan organization. He suggests that "the web depends on trust and empathy for its effectiveness and on telepathy and personal conversation for communication" (p. 184).

Status quo assumption and trust in insiders' intelligence. All the behaviors, political maneuvering and agendas of the insiders can be attributed to a fundamental assumption that underpinned their world. This we call status quo assumption (see Table 2). The insiders maintained an essentially conservative word view, which could have resulted from their prolonged, unchallenged stay at the helm of the Folklandia Pavilion. They had a plenty of opportunity to consolidate their shared expectations and background knowledge, which are the dimensions of infoculture according to Bressand and Distler (1995). A personal factor could also play a role in settling of the status quo assumption. The insiders typically had a lower education and, ageing with the Festival, had past the middle age by 2001 .

This corollary of the status quo assumption was that the insiders' way believed to be the best way. Consequently, they treasured their painfully acquired knowledge and guarded access to it. This knowledge was sanctified as a superior piece of intelligence (Table 2). Rituals and practices of protecting knowledge naturally followed. It is not only mistrust in novelties that drove this infoculture but also the insiders' fear that deviating from the old way would be destructive - not only to their position in the Pavilion but also to the well-being of the Pavilion. Thus, their particularistic worldview painted their perception of the whole. The status quo assumption was also mirrored in other artifacts of this infoculture, such as documenting aversion and computers denial. 
Table 2: Trajectory of Infoculture in Folklandia Pavilion

\begin{tabular}{|c|c|c|}
\hline $\begin{array}{l}\text { Infoculture } \\
\text { Component }\end{array}$ & Clan Era (2001-2) & Teams Era (2003) \\
\hline \multirow[t]{6}{*}{$\begin{array}{c}\text { Beliefs } \\
\text {-- } \\
\text { Behaviors }\end{array}$} & $\begin{array}{l}\text { Status Quo Assumption: Historically } \\
\text { acquired knowledge of organizing and } \\
\text { running the Pavilion should be preserved } \\
\text { within the insiders' circle. } \\
\qquad-- \\
\text { Rituals and practices of keeping knowl- } \\
\text { edge within the insider's circle and of } \\
\text { excluding the insiders. }\end{array}$ & $\begin{array}{l}\text { Transformation Assumption: } \\
\text { Professional knowledge from various do- } \\
\text { mains should be combined in functional } \\
\text { teams and used for improving income and } \\
\text { Pavilion's offerings. } \\
\text { Active acquisition of procedural knowledge } \\
\text { and more sharing of various knowledge and } \\
\text { new information in and across teams. }\end{array}$ \\
\hline & Valuing insiders' intelligence. & Valuing teams' intelligence. \\
\hline & $\begin{array}{l}\text { Aversive attitudes toward documenting } \\
\text { knowledge and methodical records keep- } \\
\text { ing. Trust in human memory. } \\
\text {-- } \\
\text { Irregular management of information and } \\
\text { knowledge, and rituals of memory recall. }\end{array}$ & $\begin{array}{l}\text { Positive attitudes toward systematic records } \\
\text { keeping, documenting new knowledge and } \\
\text { trust in technology-supported memory. } \\
\qquad-- \\
\text { More systematic management of information } \\
\text { and knowledge. }\end{array}$ \\
\hline & $\begin{array}{l}\text { Valuing paper trail and disbelief in com- } \\
\text { puters. The emerging leadership in } 2002 \\
\text { airs appreciation for computers. } \\
\qquad-- \\
\text { Use of paper trail in support to Pavilion's } \\
\text { operations. The emerging leadership in } \\
2002 \text { counters by using computers for } \\
\text { limited records management. }\end{array}$ & $\begin{array}{l}\text { Positive valuing of computer; pragmatic atti- } \\
\text { tude toward paper trail. } \\
\text { A high usage of electronic information tech- } \\
\text { nologies from operations to marketing and } \\
\text { financial management. }\end{array}$ \\
\hline & $\begin{array}{l}\text { Preference for informal oral communica- } \\
\text { tion. The emerging leadership in } 2002 \\
\text { counters by praising email for conven- } \\
\text { ience and expedience. } \\
\qquad-- \\
\text { Communicating face-to-face and via } \\
\text { telephone. The emerging leadership in } \\
2002 \text { counters by using email intensely. }\end{array}$ & $\begin{array}{l}\text { Preference for documented and sometimes } \\
\text { more formal communication. } \\
\text { Email valued for documenting capabilities. } \\
\text { Communicating via email, memos and for- } \\
\text { mal meetings. Multipurpose use of email } \\
\text { across the Pavilion. Email becomes backbone } \\
\text { to organizational memory. }\end{array}$ \\
\hline & $\begin{array}{l}\text { Excluding IS from the beliefs system. } \\
\text { Behaviors incongruent with logic of IS. }\end{array}$ & $\begin{array}{l}\text { Believing that IS are useful and needed. } \\
\text { End user systems development and intensive } \\
\text { system use. }\end{array}$ \\
\hline
\end{tabular}

Documenting aversion. As the discussion in the previous sections indicated, the insiders refused to document their knowledge and did not keep records on operations in a methodical manner. We 
term this attitude documenting aversion. From the perspective of self-preservation, the insiders could reason that documenting knowledge could have led to undesirable outcomes. Knowledge could leak to the outsiders and thereby lose its sacred character. Heretic thoughts could occur, such as the idea that the insiders could be replaced. Similarly, availability of complete, clean records on costs and on organizational performance could have raised questions concerning the background causes and possibility of different outcomes. In general, uncontrollable changes could have been triggered.

Documenting aversion can be explained in terms of Boisot's $(1987,1998)$ framework. Documenting knowledge is a form of codifying information. The simplest form of codifying is writing down what is known. Codified information increases the scope of information diffusion. Since the clan organization attempts to keep information within the power center, codification or documenting of knowledge is neither appreciated nor practiced. What was the alternative to documenting? Human memory. Instead of relying on documentation, the insiders relied on their own memory. Although this preserved their order, they had to pay the price of a painstaking recall. High time costs and information loss were the first order consequences, triggering rippled effects on organizational processes and, in the ultimate instance, organizational performance.

Hail to Spartan paper trail-computer to dumpster. The literature providing the backdrop to our concept of infoculture discussed above had identified computer technology as an important generator of infocultures (Deal \& Kennedy, 1999; Orlikowski, 1996; Orlikowski \& Gash, 1994). The clan era in 2001, however, had seen more of a paper trail than of computers and, thus, it can be characterized as a pre-computer infoculture. In 2002, computers were introduced in some major operations (tracking of expenditures, communications, marketing). Still, all this was done on the margins rather than in the mainstream infoculture, which valued paper as the technology of choice. We found that a number of Pavilion members characterized paper as "safe," "always available," "natural," and "cheap."

Although paper trail reigned, it was really used to a limited extent due to the documenting aversion attitude (see above) and the preference for oral communication (see below). When we finally obtained access to paper records, we realized that about $95 \%$ of the records preceding 2002 were paper receipts and paper notes stored in boxes labeled by Festival years. The level of organizing these records was low. The receipts were in piles held together by rubber bands, and the grouping was based on dates and types of products (e.g., drinks, food, and accessories). The notes contained some summary information, but no clear summary of overall costs and revenues could be found. Therefore, the venerated paper trail was Spartan, or meager, scanty, insufficient for the purposes of accounting and financial control.

Being anchored in the paper world, the insiders maintained an adamant anti-computer stance and managed to influence many volunteers in this direction. In interviews, anti-computer opinions were aired clearly, and we organized them in three categories. One is computer illiteracy:

I am not a computer person, and I don't know how I am supposed to use it! (An insider performing in the role of cashier)

What do we need a computer for? I can do my part well without any computer, and I don't see how it could help me. (A volunteer working on ticket sales)

Another category depicting the anti-computer stance refers to computer apprehension.

Computer, huh? I've got no clue what's going on in that thing [computer] ... How can I trust it is going to do it right? (The 2001 treasurer)

I'd rather do my work in old ways I am familiar with. I fear I can make some damage if I touch a wrong key and have the information inside a computer lost. Perhaps younger, 
trained people can see a value in computers, but not me. I do not use computers in my own business either, and I'm doing fine. (A volunteer performing in various operations)

Yet another category of anti-computer beliefs included a variant of the not invented here attitude, which can be seen as yet another reflection of the general status quo assumption.

Computer has no use in this Pavilion! Our job is to represent our cultural heritage, and that is where we should focus our efforts-not on computers. (An insider)

Why would I need a computer? I call my supplier to bring me the merchandise... I sell things I've got... I collect money, count the cash at the end of the day... I write down numbers in my notepad, and that's it! Where could I use a computer in my business? It [computer] might have place in some other parts of the Pavilion, but not here. (A souvenirs booth staff)

We lived without computers so far, why would we need them now? And there are the things we need more urgently than a computer. (A member of the core family)

Therefore, the denial of computers had several faces-computer illiteracy, computer apprehension and the not invented here attitude. Paper trail was favored. But, as already discussed, it was not used in a systematic way. Enter the rituals of recalling past solutions from human memory cited above. The result is an irregular management of information and knowledge-yet another dimension describing this infoculture.

The cracks in this infoculture, however, surfaced in 2002. Computer use was an issue of contention. The most dramatic example was that the new treasurer (an outsider) based accounting of costs on Excel ${ }^{\mathrm{tm}}$ applications, which he developed. Another big example was communication via email (see the next item below and the section on the teams era). Still, the use of computers was limited to a minority of Pavilion members and certain tasks. It appeared that the insiders neither cared much nor understood what was going on. At any rate, it appeared that they refrained from blocking publicly the outsiders.

Oral communication and IS denial. Another infocultural aspect was a tradition of oral communication. As Davenport and Prusak (1997) have pointed out, the choice of communication channels is a dimension of infoculture. The insiders' first choice was face-to-face communication, and the second was the telephone channel. They claimed that were the best way to "understand each other" and "get things right." Recall Handy's (1993) proposition that this sort of organization "depends on telepathy and personal conversation for communication" (p. 184). Oral communication is the natural choice in this context. However, what worked well within the insiders circle, was not truly appreciated by others. Some members of the emerging new leadership pointed out that "it was not easy to get the people in charge [the insiders] to talk on the phone." One obstacle was the telephone tag and another appeared to be the insiders' reluctance to return calls. These outsiders countered the mainstream infoculture by using email frequently and praising it publicly for convenience and expedience.

Note that the choice of oral communication was consistent with the attitude of documenting aversion. Oral communication left no trace, and it could be interpreted arbitrarily in later recalls. When the propensity for oral communication is coupled with documenting aversion and anticomputer values, yet another aspect of the clan infoculture emerges. Since information, communication and IT are parts of any IS, a positioning on these three aspects may indicate how IS fairs in a certain infoculture. Ouchi (1979) has suggested that IS are not a priority in a clan organization because it does not have the needs that IS are designed to fulfill. This organization does not track organizational performance in order to compare it against predefined criteria, as the market organization does. And unlike bureaucracy, the clan organization does not adhere to formal pro- 
cedures either. Therefore, there is little/no need for IS in the clan organization (cf. Hatch, 1997: 337-41).

We should note that the concept of IS implied in Ouchi's (1979) argument is also shared in the IS field: an IS is a rational means of achieving rational ends - systematic information management based on IS leads to quality information (accurate, complete, timely), which, in turn, supports certain organizational objectives. The insiders in our study did in fact deny IS as a rational means. They had an aversion toward computers and systematic records keeping and preferred undocumented communications. This denial, however, had rational ends because it helped prolong the existing clan organization. Therefore, from the perspective of the clan organization, the denial of IS, and than acceptance, is a rational means toward rational ends.

Although the IS denial was the dominant tendency in the clan infoculture of the Folklandia Pavilion it was not the only belief and behavior concerning IS. The organization already carried the seeds of its antipode that originated among the outsiders in 2002. These seeds were going to transform the Pavilion and bring it into the next phase in its historical trajectory, which is the topic of the next section.

In summary, the infoculture of the clan era was characterized by a status quo assumption, trust in insiders' intelligence, documenting aversion, disbelief in computers, valuing of paper trail, oral communication, and denial of IS. In contrast, a marginal subculture emerged in 2002, opposing the mainstream infoculture in many respects.

\section{Infopolitics and Infoculture in Teams Era}

The Era of Teams dawned in 2003. A new leadership was established that enlisted some members of the emerging new leadership from 2002, a number of new volunteers in lead positions, and only one member from the old insiders circle. The recruitment/selection and initial radical changes of the organization of the Pavilion was the deed of the coordinator, coordinator assistant and program leader. These three worked out many things as a coherent team of professionals. The next significant change was that the Pavilion was moved from its old "underground" to a school in a wealthy neighborhood. The seating capacity was tripled, and access to modern facilities for catering and entertainment obtained. A new function called Kids Corner was introduced, the Souvenirs function was eventually put on track with diversified offerings from food to video and music products, guest musicians were brought from out of town to enrich the artistic program, and more was done on the marketing side (see organization chart in Figure 3).

A new organization of the Pavilion was established. Organizational structure became more differentiated as new functions were introduced and lines of reporting defined. Each function was carried by a team, which was headed by a leader. Each leader reported to the coordinator, although there were some crossed lines of reporting, bringing in an aspect of the matrix organization (e.g., the folk dance group leader reported both to the program leader and the coordinator). Thus, the Pavilion became organized in a more complex way that combined characteristics of team organization and flexible hierarchy.

\section{Fresh Air in Infopolitics}

Terminating the knowledge monopoly of the insiders decisively changed infopolitics in the Folklandia Pavilion. From the perspective of information diffusion (Boisot, 1987, 1998), the new infopolitics increased diffusion of information in its various forms, thus destroying the pattern of diffusion localized in the insiders' circle. The concepts of centralization/decentralization of information and IT that help understand infopolitics in general (Hanseth et al. 2001; Markus, 1983; Orlikowski \& Yates, 1994; Travica, 1999; Zuboff, 1984) are useful in explaining these changes. 
While the old regime centralized information to its exclusive circle of power, the new regime pulled toward decentralization of information and IT.

As indicated in Table 1, the trajectory of the new infopolitics had origins in the clan era since the former was emanating as an antipode to the clan infopolitics. The new infopolitics evolved around the assumption of organizational change, which covered many bases - from organizational structure, politics and culture to leadership and management. Building the new organization was coupled with the acquisition of new knowledge, and learning became the main imperative. This imperative had a bearing on infopolitics by drawing a demarcation line between those who accepted it and those who did not. The Pavilion facilities, its new environment, and the challenges of its new functions and an increased volume of operations were a terra incognita for all. The challenge of the unknown and the urge to learn discouraged those who believed only in the old ways and resisted learning the new. Indeed, the majority of the old insiders could not see themselves in the new order and excluded themselves from the Pavilion. The insiders offered several justifications in public: "I do not know where the Pavilion is now;" "I don't know how to get there;" "The new Pavilion is far from my home/work;" "I do not know anybody in that new neighborhood;" "I got no clue how things work there."

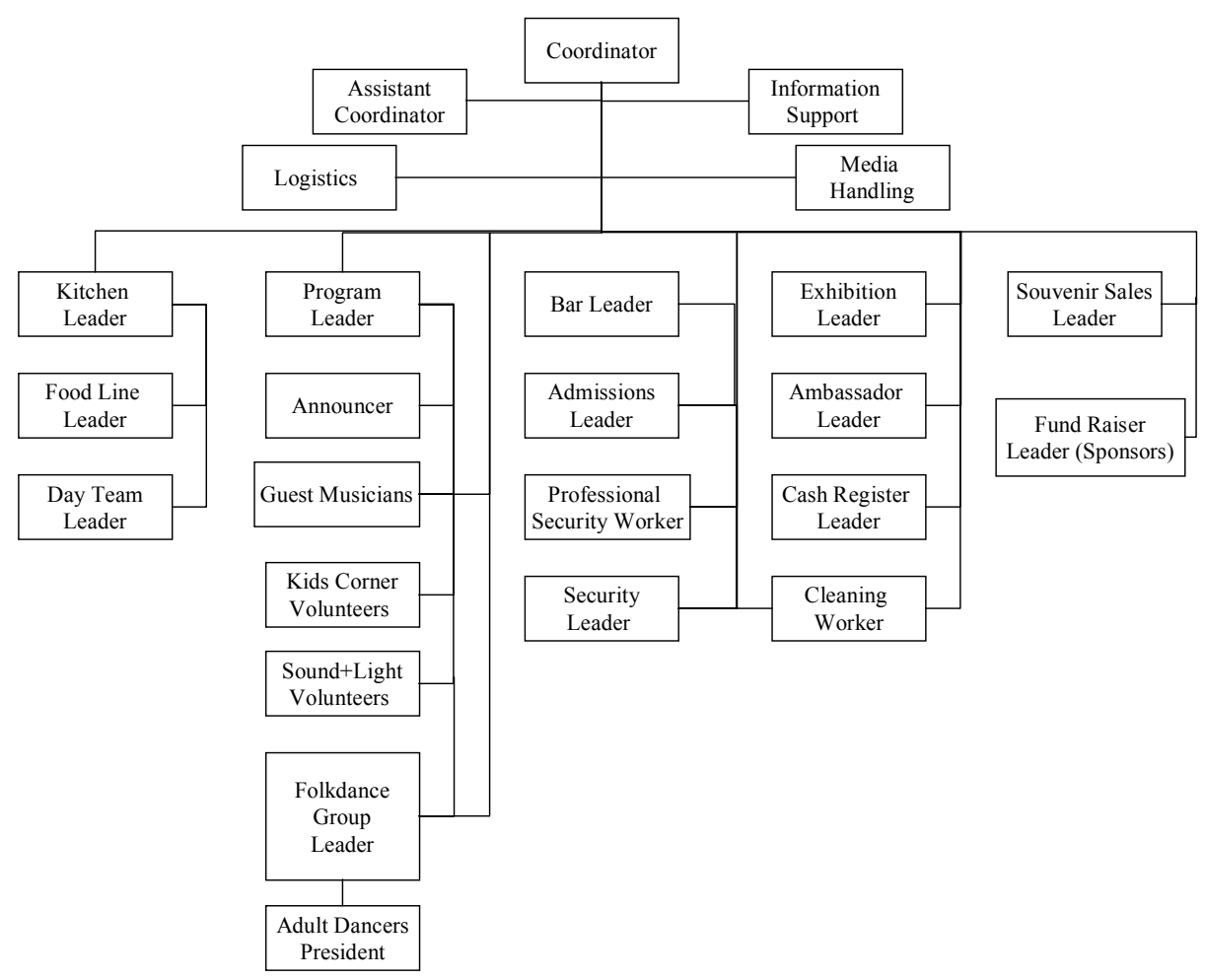

Figure 3: Organizational Chart of the Folklandia Pavilion in Phase II

In addition to knowledge of organizing and running the Pavilion, knowledge of modern IT and information management consolidated the new basis of power. The new leadership had an advantage in this respect - with an exception or two, leaders of all the teams were minimally at the intermediate level of computer literacy. Other Pavilion members typically had less developed computer skills. The difference was critical in cases of applications used on a daily basis, such as email. A new mode of power differentiation developed on this basis, thus corroborating previous evidence that the speed, direction, content and pattern of information flows have to do with power (Danziger et al., 1982; Markus, 1983). A remarkable example of a power loss associated with 
technological change was the president of the Board of the Pavilion's sponsoring organization. Of all the Board members, this person lagged in adopting email. An apparent consequence was that he was always out of the loop of new information, which was circulated fast via email. This was visible at meetings, where he struggled to catch up and sometimes failed to act as an effective decision maker.

One volunteer described the overall changes at the end of the Festival succinctly: "It felt as if the windows that were toughly closed over a long time were opened at last to let the fresh air in." In addition to letting the fresh air of new knowledge in, energy was spared by the cessation of poignant political and infopolitical battles of the past. The new infopolitics in particular propelled more open communication channels. The sharing of knowledge and information was continuously stimulated, and the new leadership made an effort to make public most of the newly created information and knowledge. Thus, the diffusion of information was significantly increased (Table 1). In the terminology of Davenport and Prusak (1997), the new infoculture showed a preference for facts over rumors.

Images of the Pavilion being solely a "homey, affordable dining place" (the vested organizational vision of the old insiders) gave way to the slogan "the Pavilion is a competitive economic enterprise." The team at the Pavilion's helm (the coordinator, assistant coordinator, and program chair) was providing a didactic example of this business-focused vision. They functioned effectively as true professionals; although not all of them related to each other in private life (the coordinator had links with two other members, while these two were distanced by some old unresolved dispute). Putting professionalism before private interest sent the message of how business logic could be brought to the fore in this enterprise, which blended aspects of volunteer and small business organization.

\section{Incubation of New Infoculture in Teams}

These changes were complemented by a major transformation of infoculture in the Folklandia Pavilion. First, the status quo assumption of the old infoculture was no longer in circulation. Instead, the assumption of transformation, which was initiated by the rebelling outsiders in the clan era, was brought to full blossoming. Functional teams became the central change agent, guided by the new leadership. These teams were nurtured as a new form of intelligence, driven by two clearly communicated strategic goals - to increase the Pavilion's income/profit margin and to improve the Pavilion's overall offerings. The learning process reached beyond Pavilion walls as the new leadership made an effort to acquire externally more advanced methods of organizing and management (e.g., from other pavilions and from appropriate domains of professional knowledge). The ideas acquired this way would then be incubated in the functional teams in order to facilitate ripening of solutions fit to the Pavilion's characteristics. New procedural knowledge was immediately shared via email and, occasionally, in meetings - within teams and between them.

Positive attitudes toward systematic records keeping and information management in general were planted and systematically cultivated in the new infoculture. This was related to the regularity in information and knowledge management that once were considered subversive political practices (see above). For example, the new leadership used every opportunity to point out how a lack of historical records, work manuals and other documentation produced loss of time, resources and money. These were moments of a dramatic reinforcement of the values of maintaining a proper information management. In one such situation, the coordinator practically demonstrated to some team leaders and the Sponsoring Organization's Board that the lack of a procedure for determining proportions of meal ingredients was a likely cause of loss in the food income in the past. 
The new leadership staked much of the new infoculture on affirmative valuing of computer technology. Paper trail continued to be used where it was useful. This blending of IT types, in spite of the strong predilection for computers, suggests that the new infoculture took a rather pragmatic approach. Again, this was in stark contrast with the dogmatic inclination toward paper and the computer denial that characterized the old infoculture. Computers were introduced in support to planning and a wide range of operations. For instance, most of accounting and financial data (including transactions with the Pavilion's bank) were managed electronically. This was an extension of changes introduced in 2002, and an example of end-user systems development. Another big example of IT deployment concerns marketing. A Web site was developed and advertised to travel agents and media, with the ultimate goal of attracting more visitors to the Pavilion (travel agents participated in the process of bringing tourists from the United States to the Folks Festival). This was another example of end-user system development. The initial idea of developing a few pages that would briefly inform on the artistic program, show times, menu, and driving directions grew up into a more ambitious project. New pages were developed in a seemingly haphazard way, each adding a new detail and helping to deepen and broaden the picture of the Pavilion. The site received some affirmative evaluations from external players, and the Pavilion's volunteers liked seeing their names and pictures on it. However, a formal evaluation of the effects of the site was never conducted.

If the proportion of paperwork vs. digital processing is considered an aspect of infoculture (Sarker \& Lee, 2000), the new infoculture in the Folklandia Pavilion tilted the proportion toward the digital side. Intensive use of digital IT was extended into Festival days. Two computers connected to data projectors and TV screens were used to run slide presentations. The presentations supported the artistic program and featured a list of the Pavilion's sponsors, thus achieving a twopronged benefit. In addition, sound masters connected a PC to the sound system, and managed the music playback this way. This allowed for a more flexible programming scheme since the selection of folk dance tunes could be easily rearranged from show to show. All this helped to improve the delivery of the artistic program. Applications of Excel ${ }^{\mathrm{tm}}$ were also used for tracking and processing the admission and income figures on the spot. were used for this purpose. Improvements in reporting resulted. For example, cash flow information was completed and made public by the end of each Festival day. Comparisons with the performance in the previous year were also generated. This information was, then, filtered into reports prepared for different audiences - the Pavilion staff, the Board of the Sponsoring Organization, and the Festival Agency. The reports were emailed and dispatched in paper form. They were also stored as part of organizational memory for future use.

\section{Email-Based Memory}

In contrast to the predominance of oral informal communication of the clan era, the new infoculture favored documented and more formal communication. Communications between the Pavilions leadership and the Board of the Pavilion's sponsoring organization acquired a written standardized form. The coordinator introduced a report for bi-weekly meetings with the Board that contained four sections: (1) Tasks Accomplished, (2) Tasks To Do, (3) Pavilion's Needs, and (4) Real/Potential Problems. These reports were distributed by both e-mail and mail and they served as the main vehicle for planning and control execution of the Pavilion's preparations.

There was no real planning behind the selection of kinds of digital IT used in the Pavilion. The main guide was information needs. For example, the need to track the performance of the Pavilion better than in the past led to electronic management of accounting and financial data. Another factor was availability of technology, since all software and hardware used were in private possession of the Pavilion members. Enthusiasm of the volunteers was responsible for the end-user 
development (the Web site, Excel ${ }^{\mathrm{tm}}$ applications). Personal preferences were likely to play a role as well. The typical example was email, which painted remarkably the new infoculture.

In 2002, the use of email was a behavior belonging to a counter-infoculture. A method of indoctrination the emerging new leadership used was to make themselves unavailable via the telephone, while answering promptly to both telephone and email messages. In the teams era, email became a true "killer" application with a high adoption rate. If convenience and expedience were the benefits that propelled email in 2002, the documenting capability promoted email into the key technology of organizational memory in 2003. Some of the 2002 email folders became a repository of information for a number of volunteers who learned how useful could be old email messages containing descriptions of certain organizational procedures, ideas, traces of problem solving and decision making, and supplier data. Analysis of a convenient sample of email folders indicated existence of the genres defined by Orlikowski and Yates (1994)-memo, dialogue, proposal, and ballot. The content of a memo message would be the documentation concerning scheduling (e.g., a breakdown of tasks against a timeline), purchasing, sales and inventory reporting (e.g., the treasurer's reports on daily cash flows), instructions (e.g., how to set up dishwashing sinks), decisions, or authority recommendations. A message in the dialogue rubric would cite parts or entire messages and respond to these; thus, the term response signifies this sort of message as well. A proposal message would contain a stimulus for thinking and action (e.g., "Can we do something with the sound, which is still bad?" or "I think that the beer garden should offer more than beer-music, discrete lights, a special atmosphere"). A ballot would contain someone's invitation to taking a vote or one's vote (e.g., "What do you think about setting up a Kids Corner in our Pavilion?").

We identified yet another genre we call reminder. Many messages resembled the form of dialogue, but their purpose was not just to respond to a cited message. Instead, a reminder message would cite a memo (report, instructions, decision, authority recommendation) in order to develop a proposal, initiate vote, or create new/extend old memos. For example, one person noted via email that some younger volunteers showed a lack of care for the inventory in the rented facilities, and asked rhetorically if something should be done about that (proposal). This sparked a chain of messages with relevant observations (dialogue) or with ideas about solutions (proposal). The next in the chain of messages was an email from the assistant coordinator that summarized the problem, cited some of the previous messages, and raised the question: "Should we make a guide on volunteers' behavior?" This message was followed by yes/no votes. Therefore, the assistant coordinator's message belongs to the reminder category because it used cites and initiated voting.

Reminder messages showed up in external communication as well. The new leadership had to maintain continuous contact with the representatives of the rented facilities as well as with a partner pavilion, which was going to use the same facilities in the alternate week of the Festival. Being able to pull out previous decisions and policy statements (both are in the memo category) turned out to be very useful in certain situations. In one of them, the building was double booked for the final rehearsal, and the coordinator successfully used his old email with a booking request (a memo) to prove his booking (reminder). In another case, the coordinator used a reminder email citing an important promise of a representative of the facilities that the representative was denying. Faced with the documented promise, the representative balked. It is apparent from this discussion that a completely new corpus of values, norms and behaviors carved an essential role for email in this infoculture. Email became par excellence a technology of management at different levels and in various organizational domains, particularly used for informing, coordinating, negotiating, planning, scheduling, and decision making.

The emphasis on email in this infoculture had a good fit with the beliefs on both documenting practices and on computers. Put together, these aspects indicate that a belief in IS as rational 
means for achieving performance goals was superior in this new infoculture. New information and knowledge was created, shared and maintained in a more systematic way than ever. This finding parallels the indication from Orlikowski's (1996) study that assumptions and values concerning preservation of knowledge could be a key aspect in a new culture.

In brief, the sections above discussed findings that address the first part of the research question concerning the aspects of infopolitics and infoculture in the Folklandia Pavilion. The second part of the research question addressed the relationships that infopolitics and infoculture formed with organizational performance, which is the topic of the next section.

\section{Improved Performance}

Changes in infopolitics and infoculture of the Pavilion coincided with improvements in the financial bottom line. As Table 3 shows, all financial indicators increased considerably in 2002 and 2003. In particular, profit ratios are significant: while only $38 \%$ of the revenue in 2001 was filtered into the gross profit, this figure increased to close to $60 \%$ in 2002 and 2003 . This means costs of sales were brought under certain control already in 2002. Although the clan organization still reigned as the discussion above showed, it was challenged by the emerging new leadership that had fingers on some important money buttons (purchasing, tracking expenditures, and income). Some improvements in financial discipline followed. Further improvements were achieved in 2003, even though the gross profit-revenue ratio was somewhat depressed by higher costs of sales cause by a larger volume of operations. Net profit gains are apparent from the data, although, due to incomplete financial records, the figures are partly based on extrapolation. As Table 3 shows, the net profit exhibits hikes in 2002/3 in contrast to the flat performance in 2000/1. Note that the net profit in 2003 could have reached 19,000 without some historically new categories of costs (e.g., charges for hiring professional security service) and unexpected losses (see below).

Qualitative assessments of the pavilion performance confirm the same increasing trend. During the Festival in 2003, the visitors (both ordinary persons and various officials) and media appreciated what the Folklandia Pavilion offered. Some of the typical comments were: "This is one of the best pavilions"; "Everything was much better organized than before"; "I felt that every staff knew what they were doing"; "The service was excellent"; "I really had fun." A number of team leaders and other volunteers also made positive remarks regarding the management and operations of the Pavilion.

The tightened financial discipline in purchasing and other expenditures in 2002 was a result of partial changes in managing the Pavilion. Performance improvements in 2003 resulted from changing the organization and further improving its management. Part of these changes happened in the domains of infopolitics and infoculture. We argued above that the fundamental conservatism in infopolitics and infoculture in the clan era kept new people and new ideas at margins. Confronting the old way in 2002 and overthrowing it in 2003 meant instituting a new infopolitics and infoculture. The net effect of changing these was in improved efficiency and effectiveness of many organizational processes. A dimension of a possibly large importance was what Sarker and Lee (2000) call "match between technological infrastructure and process efficiency needs." The many changes of IT infrastructure that the Folklandia Pavilion experienced in the teams era led to a better match between IT and process efficiency needs. Technology helped meet efficiency requirements of a number of processes, among which the most deficient used to be those of knowledge management, accounting/financial control, performance tracking, scheduling, and coordinating. It follows from these premises that the changes in infopolitics and infoculture contributed to improvements in the Pavilion's performance. 
Table 3: Financial Performance of the Folklandia Pavilion

\begin{tabular}{|c|c|c|c|c|}
\hline Financial Figure & 2000 & 2001 & 2002 & 2003 \\
\hline Revenue & $\$ 19,000.00$ & $\$ 18,400.00$ & $\$ 29,700.00$ & $\$ 48,800.00$ \\
\hline Gross Profit & $\$ 7,500.00$ & $\$ 7,000.00$ & $\$ 17,300.00$ & $\$ 29,000.33$ \\
\hline Gross Profit in Revenue & $39.00 \%$ & $38.00 \%$ & $57.00 \%$ & $59.00 \%$ \\
\hline Net Profit & $\$ 5,700.00^{*}$ & $\$ 5,520.00^{*}$ & $\$ 9,000$ & $\$ 13,036$ \\
\hline Net Profit Change \% & - & -3 & 63 & 45 \\
\hline Net Profit in Revenue & $30.00 \% *$ & $30.00 \% *$ & $30.30 \%$ & $26.71 \%$ \\
\hline Visitors & $\mathrm{NA}$ & NA & 2,085 & 3,043 \\
\hline Visitors/Show Average & NA & NA & 83 & 122 \\
\hline
\end{tabular}

Note: All figures are in Canadian dollars. * Estimates based on the $30 \%$ net profit/revenue ratios in 2002 and 2003.

The teams era was not spared of problems. Although the Pavilion was improved in many aspects, some processes did not function well in the beginning. For example, the Kitchen function experienced difficulties with staffing and coordination. A newly created guide on rights and obligations that defined between appropriate and inappropriate behaviors was not observed equally by all the functions, and a few instances of visible transgressions were noted. Furthermore, a lack of information on the part of the Bar function was responsible for violating special sponsorship deals about eligible brands of beer for sale. Consequently, the Pavilion had to pay a fine to the dealmaker (the Festival Agency), which eroded the net profit margin.

In summary, the era of teams introduced a new infopolitics and infoculture in the Folklandia Pavilion. The knowledge monopoly of the old regime was dismantled and more open communication and sharing of information in its various forms was practiced. Teams became the centerpiece of the new order, and an entire email culture emerged. The Pavilion achieved a higher level of performance.

\section{Limitations of the Study}

The case study presented in this article has several limitations. The first refers to the rather unique type of organization under study. It was a hybrid of volunteer and small business organization that is not very common. This unique organization had certain flexibility due to the temporary staff and leadership that allowed rather swift organizational changes to take place within a relatively short period. However, this unique character imposes limits to generalizing findings of the study.

Second, the IT involved in the case is either pre-electronic (Phase I) or basic (Excel ${ }^{\mathrm{tm}}$ applications, email) with rare instances of higher types (Web technology). The choices and particular uses of IT were dependent on the particular people involved. They brought their own IT into the Pavilion business, and evolved the spectrum of IT use according to their capabilities. For example, although the demonstrated straightforward use of email in support to organizational memory was an interesting invention, one can certainly think of various alternatives with richer retrieval and organizing capabilities. Therefore, it could be challenging to look for cases that are comparative on the IT infrastructure and its use.

Third, a high investment of time in this longitudinal investigation poses a bar in terms of replicating the study. Fourth, findings on causal connections discussed in the section on the financial 
gains of the reorganized Folklandia Pavilion draw on a simplified modeling. The new infoculture and infopolitics could have led first to process gains, and then improved process efficiency and effectiveness could translate directly into monetary gains. These process aspects and their effects, however, were just tentatively addressed in this article because the focus has been on infopolitics and infoculture.

The fifth limitation follows from those listed above: the case study can be taken only as a limited test of the part of the IVO framework concerning infoculture and infopolitics. New tests on different types of organizations with different types of IT and information and knowledge management are needed for validating further the concepts of infoculture and infopolitics and the broader IVO framework.

\section{Summary and Discussion}

In this article, we presented new concepts of infoculture and infopolitics through definitions, a review of organizational and IS literature, and a case study. We first defined infopolitics in terms of power, agendas, and fights/flights that concern organizational information and IT. We discussed the literature that inspired this concept (Barley, 1986, 1990; Beniger 1986; Boisot, 1987, 1998; Crozier, 1964; Danziger et al., 1982; Davenport \& Prusak, 1997; Feldman \& March, 1981; Greenbaum \& Kyng, 1991; Hanseth et al., 2001; Iivari \& Lyytinen, 1999; Markus, 1983; Pfeffer, 1981; Orlikowski, 1992; Orlikowski \& Yates, 1994; Spears \& Lea, 1994; Sproul \& Kiesler, 1991; Zuboff, 1984). Further, we defined infoculture in terms of stable beliefs (assumptions, values, norms, attitudes) and behaviors (work practices, rituals, social dramas, and communication) that refer to organizational information and IT. A sample of the literature that inspired our concept of infoculture was, then, discussed (Bressand \& Distler, 1995; Davenport \& Prusak, 1997; Deal \& Kennedy, 1999; Jaques, 1952; Orlikowski, 1994, 1996; Sarker \& Lee, 2000; Schein, 1991).

In the second part of the article, we presented an early test of infopolitics and infoculture realized through a case study of a festival organization in Canada - the Folklandia Pavilion. This was a longitudinal 25 month-long study that tested the concept infoculture and helped develop and test the concept of infopolitics. The study used a triangulated methodology for data collection that consisted of ethnography, interviewing and document analysis. The data collection and partly data analysis relied on a process of interpretivist inquiry whose basic unit consisted of the asking, learning, and hypothesizing steps. These steps were used as a loop that was iterated for each item of the research agenda until a preliminary finding was reached. The same process was used for arriving at the final research question: What are the aspects of infopolitics and infoculture in the organization under study, and how do they relate to other organizational aspects and organizational performance?

The main findings is that that the Folklandia Pavilion passed through two development phases, each characterized by different infopolitics and infoculture, and each having different effects on the Pavilion's performance. First was the phase of a clan organization (Handy, 1993; Ouchi, 1979,1980 ). It covered years $2001 / 2$, when a group of seasoned volunteers - the insiders - used a monopoly of knowledge and information as the basis of power over the majority of the Pavilion members - the outsiders. The insiders' agenda was to preserve the status quo in the distribution of information and in use (or better disuse) of IT. Political maneuvering of the insiders was in function of these goals, and they blocked action that would threaten to transform the Pavilion into something else but their "homey, affordable dinning place."

In the domain of infoculture, the insiders followed an assumption of status quo, and exercised rituals and work practices aiming at keeping knowledge within their circle. Other aspects of this infopolitics included aversive attitudes toward documenting knowledge and methodical records keeping, a preference for human memory over technology-supported one, valuing paper trail over 
computers, favoring informal oral communication over mediated and formalized one, and excluding IS from the beliefs system. The insiders exercised consequent behaviors on each count. They were deeply vested into the world they were familiar with and firmly believed theirs was the best of all possible worlds.

Unfettered in 2001, the clannish infopolitics and infoculture faced a challenge of the outsiders led by an emerging new leadership. The challenge included a struggle for a more systematic information management, a push for using computers, and planting a vision of competitive economic enterprise. These can be considered aspects of a subversive infopolitics and infoculture countering the mainstream counterparts. The division in the Pavilion's infopolitics resembles the conflicts around organizational information and IT described in the literature (Barley, 1986, 1990; Danziger and associates, 1982; Hanseth et al., 2001; Markus, 1983; Orlikowski, 1992). The division in the Pavilion's infoculture confirms the possibility of fragmentation of organizational beliefs and behaviors evidenced in the literature (Kunda, 1992; Orlikowski, 1996). Therefore, the clan organization brought to bear the seeds of its own destruction.

Building on the changes initiated in 2002 that could be understood in terms of an unfreezing stage in organizational development, a radical transformation of the Pavilion ensued in 2003. The removal of the ancient regime was rather swift. Probably owing to the flexible character of organizational membership, the old organization was dismantled in a process mimicking radical changes of corporate crisis management. The insiders helped the change by opting to stay out of the Pavilion. The Pavilion was moved to a wealthy neighborhood, and a new organization was established based on functional teams connected into a shallow, flexible hierarchy. The termination of the insiders' knowledge monopoly gave way to a new power distribution. A significant segment of the power basis of the new regime was knowledge of using newly deployed modern IT and thereby supported information management. This finding corroborates previous evidence on the relationships between IT and power (Barley, 1986, 1990; Markus, 1983; Zuboff, 1984) and between knowledge and power (Barley, 1986, 1990; Crozier, 1964; Zuboff, 1984). The power change in the Folklandia Pavilion also confirms the proposition that digital IT is a flexible technology that can be used for supporting various interests (Danziger et al., 1982; Zuboff, 1984). In transforming the infopolitics, the outsiders also pushed for overall modernizing of information and knowledge management, open communication channels, and bringing to fruition the vision of a competitive economic enterprise.

The infoculture was also part of organizational transformation. The new infoculture was premised on an assumption of transformation based on professional knowledge and continuous learning. The teams carrying various functions in the Pavilion became agents of intelligence suitable to the new era, incubators of new ideas brought from the Pavilion's environment, and developers and testers of new methods of work. A vision of economic enterprise provided guidance-increase income, improve service. In a stark contrast to old ways, the new organization deployed a more systematic management of information and knowledge, and used various applications to support this. Digital IT and IS posed prominently both in the value system and in work practices. Through practice and ritualistic reinforcement of values attached to it, email was promoted into a key technology in the new infoculture. Email formed the technological foundation of organizational memory. This memory was instantiated in the genres of memo, dialogue, proposal, ballot (Orlikowski \& Yates, 1994) and in a newly discovered "reminder." We have defined reminder message as the one that cites some memo in order to develop a proposal, initiate vote, or create new/extend old memos. This sort of message was used beneficially both within the Pavilion and in communication with external stakeholders. From the management perspective, email found place in informing, coordinating, negotiating, planning, scheduling, and decision making activities. 
The discovery of an entire infoculture corroborates previous evidence that new IT can trigger broad cultural changes (Orlikowski, 1996). In contrast to this study, however, our case shows that the changes could be not only opportunistic but also a result of a planned, concentrated effort. Note, however, that different types of organizations and IT are addressed in these studies, and that the organization in our study has no permanent membership. Furthermore, contrary to Deal and Kennedy's (1999) cautioning about undesirable cultural effects of computers, we found that computer-related changes in the Folklandia Pavilion were beneficial. The proposition of these authors that computers can be instruments of breaking old social ties turned to be true. However, these ties belonged to an obsolete clan organization that hindered the development of the organization studied, and so breaking them created opportunities for improving the organization and its performance.

In summary, this article has introduced the concepts of infopolitics and reported on exploring these in a filed study. Specifically, the dimensions of infopolitics we detected in the literature are:

- The speed, direction, content and pattern of information flows (Danziger et al., 1982; Markus, 1983);

- Automation of control (Danziger et al., 1982; Orlikowski, 1992; Zuboff, 1984);

- Centralization/decentralization of information and IT (Hanseth et al. 2001; Markus, 1983; Orlikowski \& Yates, 1994; Travica, 1999; Zuboff, 1984); and

- Codification and diffusion of information (Boisot, 1987, 1998).

Our case study has confirmed all the dimensions but automation of control, and added these:

- Knowledge monopoly vs. sharing (has a similarity with the centralization/decentralization dimension);

- Regularity in information and knowledge management;

- Closed loop vs. open loop communication;

- Computer denial vs. embracing; and

- Vested organizational vision.

With regard to infoculture, the dimensions detected in the literature are:

- The choice of communication channel, information sharing practices, and preference for facts or rumors (Davenport \& Prusak, 1997);

- Shared expectations and background knowledge (Bressand \& Distler, 1995);

- Assumptions regarding instrumentality of IT and information in accomplishing performance goals (Orlikowski \& Gash, 1994);

- The assumption concerning preservation of knowledge, and values and stories of preserving knowledge via documenting it (Orlikowski, 1996); and

- The proportion of paperwork vs. digital processing, match between technological infrastructure and process efficiency needs, and properties of inter-departmental communication and coordination (Sarker \& Lee, 2000).

Our case has confirmed all these dimensions but the one on interdepartmental communication, and added these aspects:

- The orientation toward change of information and IT;

- Beliefs about the character of intelligence; and

- Beliefs concerning worth of computers, paper, and IS. 
The research question also asked about relationships between infopolitics and infoculture, on the one side, and organizational characteristics and performance, on the other. As the discussion showed, the team infoculture and infopolitics in the Folklandia Pavilion were related to a number of organizational dimensions in a manner that was beneficial for the Pavilion. In particular, better information accrued for the management and stakeholders. Better cost accounting supported a tighter financial discipline. Planning, control, operations management and execution, strategizing, coordination, and personnel management benefited from the new infopolitics and infoculture as well. Communication became more efficient and supportive of better planning and control.

Richer and faster organizational memory utilizing email helped save time and money and be more effective. As a result, financial performance of the Pavilion improved with the crackdown of the clan era and dawning of the teams era. Service improvements followed the suit. These findings suggest that both infopolitics and infoculture have played a role in improving management and organizational performance.

Due to a number of limitations, including the uncommon hybrid design of the organization under study and its specific IT infrastructure, this case study can be taken only as a limited test of the part of the IVO framework (Travica, 2003) concerning infoculture and infopolitics. Initial evidence on these dimensions is in place, and more research is now needed to test these and discover new ones. It is possible that sets of new dimensions will result from research. Consequently, methods of organizing them will be needed. In this article, we resorted to using a dyadic typology of organizational designs (the clan and teams based organization) for categorizing the discovered dimensions of infoculture and infopolitics. Continued attention to the typology issue is necessary.

Our findings also suggest that infoculture and infopolitics are the phenomena that can have importance for both organization theory and IS theory as well as for practical management. However, further validation of this proposition is needed through investigating both comparable and different organizations and IT infrastructures. Following these research directions could facilitate comprehending infoculture and infopolitics. Consequently, the parent IVO framework would also be advanced along with its essential academic goal - the cross pollination between organizational and IS theory - and its practical purpose - helping management and organizational development.

\section{References}

Bxzarley, S. (1986). Technology as an occasion for structuring: Evidence from observations of CT scanners and the social order of radiology departments. Administrative Science Quarterly, 31, 78-108.

Barley, S. (1990). The alignment of technology and structure through roles and networks. Administrative Science Quarterly, 35, 61-103.

Baskerville, R., \& Myers, M. (Eds.). (2004). Special issue on action research in information systems: Making IS research relevant to practice (Foreword). MIS Quarterly, 28(3), 329-335.

Beniger, J. (1986). The control revolution: Technological and economic origins of the information society. Cambridge, MA: Harvard University Press.

Boisot, M. (1987). Information and organizations: The manager as anthropologist. London: Fontana/Collins.

Boisot, M. (1998). Knowledge assets: Securing competitive advantage in the information economy. Oxford, UK: Oxford University Press.

Bressand, A., \& Distler, C. (1995). La planéte relationelle. Paris: Flamarion.

Ciborra, C. (Ed.). (1996). Groupware and teamwork: Invisible hand or technical hindrance? Chichester, NJ: John Wiley.

Clegg, S. (1990). Modern organizations: Organization studies in the postmodern world. London: SAGE.

Cohen, E. (1999). Reconceptualizing information systems as a field of the transdiscipline informing science: From ugly duckling to swan. Journal of Computing and Information Technology, 7(3), 213-219. 
Crozier, M. (1964). The bureaucratic phenomenon. Chicago: University of Chicago Press.

Danziger, J., Dutton, W., Kling, R., \& Kraemer. K. (1982). Computers and politics: High technology in American local governments. New York: Columbia University Press.

Davenport, T., \& Prusak, L. (1997). Information ecology: Mastering information and knowledge environment. New York: Oxford University Press.

Deal, T., \& Kennedy, A. (1999). The new corporate cultures: Revitalizing the workplace after downsizing, mergers, and reengineering. Reading, MA: Perseus Books.

Greenbaum, J., \& Kyng, M. (Eds.). (1991). Design at work: Cooperative design of computer systems. Hillsdale, NJ: Lawrence Erlbaum.

Erdelez, S. (in press). Information encountering. In K. E. Fisher, S. Erdelez, \& E. F. McKechnie (Eds.), Theories of information behavior. Medford, NJ: Information Today.

Feldman, M. \& March. J. (1981). Information in organizations as signal and symbol. Administrative Science Quarterly, 26(2), 171-186.

Goldman, S. L., Nagel, R. N., \& Preiss, K. (1995). Agile competitors and virtual organizations: Strategies for enriching the customer. New York: Van Nostrand Reinhold.

Handy, C. (1993). Understanding organizations. New York: Oxford University Press.

Hanseth, O., Ciborra, C., \& Braa, K. (2001). The control devolution: ERP and the side-effects of globalization. The Data Base for Advances in Information Systems, 32(4), 34-46.

Hatch, M. J. (1997). Organization theory: Modern, symbolic, and postmodern perspectives. Oxford-New York: Oxford University Press.

Hiltz, S. \& Turoff, M. (1978). The network: Nation human communication via computer. Reading, MA: Addison-Wesley.

Hunter, G. (2004). Qualitative research in information systems: An exploration of methods. In M. Whitman \& Woszczynski, A. (Eds.), The handbook of information systems research (pp. 291-304). Hershey, PA: Idea Group Publishing.

Iivari, J., \& Lyytinen, K. (1999). Research on information systems in Scandinavia: Unity in plurality. In W. Currie \& B. Galliers (Eds.), Rethinking information systems: An interdisciplinary perspective (pp. 57102). Oxford, MA: Oxford University Press.

Janis, I. (1982). Groupthink: Psychological studies on policy decisions and fiascoes (2 ${ }^{\text {nd }}$ ed.). Boston: Houghton Mifflin.

Jaques, E. (1952). The changing culture of a factory. New York: Dryden Press.

Klein, H., \& Myers, M. (1999). A set of principles for conducting and evaluating interpretive fields studies in information systems. MIS Quarterly, 23(1), 67-94.

Kunda, G. (1992). Engineering culture: Control and commitment in a high-tech corporation. Philadelphia: Temple University.

Lee, A. (1989). A scientific methodology for MIS case studies. MIS Quarterly, March, 33-50.

Lewin, K. (1948). Resolving social conflict. New York: Harper.

Markus, L. (1983). Power, politics, and MIS implementation. Communications of the ACM, 26(6), 430444.

Martin, J. (1992). Cultures in organizations: Three perspectives. New York: Oxford University Press.

Mintzberg, H. (1979). The structuring of organizations: A synthesis of the research. Englewood Cliffs, NJ: Prentice Hall.

Orlikowski, W. (1992). The duality of technology: Rethinking the concept of technology in organizations. Organization Science, 3(3), 398-427.

Orlikowski, W. (1996). Evolving with Notes: Organizational change around groupware technology. In C. Ciborra (Ed.), Groupware and teamwork: Invisible hand or technical hindrance? (pp. 23-59). Chichester: John Wiley. 
Orlikowski, W., \& Barley, S. (2001). Technology and institutions: What can research on information technology and research on organizations learn from each other? MIS Quarterly, 25(2), 145-65.

Orlikowski, W., \& Gash, D. (1994). Technological frames: Making sense of IT in organizations, ACM Transactions on Information Systems, 12(2), 174-207.

Orlikowski, W., \& Yates, B. (1994). Genre repertoire: The structuring of communicative practices in organizations. Administrative Science Quarterly, 39, 541-574.

Ouchi, W. (1980). Markets, bureaucracies, and clans. Administrative Science Quarterly, 25, 129-141.

Ouchi, W. (1979). A conceptual framework for the design of organizational control mechanisms, Management Science, 25(9), 833-848.

Pfeffer, J. (1981). Power in organizations. Marshfield, PA: Pitman.

Sarker, S., Lee, A. (2000). Using a case study to test the role of three key social enablers in ERP implementation. In S. Ang, H. Krcmar, W. Orlikowski, P. Weill, \& J. I. DeGross (Eds.), Proceedings of the 21st International Conference on Information Systems (pp. 414-425), December 10-13, 2000 Brisbane, Australia.

Schein, E., (1991). What is culture? In P. J. Frost, L. F. Moore, M. R. Louis, C. C. Lundberg, \& J. Martin (Eds.), Reframing organizational culture. Newbury Park, CA: SAGE.

Spears, R., \& Lea, M. (1994). Panacea or panopticon? The hidden power in computer-mediated communication. Communication Research, 21(4), 427-459.

Sproul, L., \& Kiesler, S. (1991). Connections: New ways of working in the networked organization. Cambridge, MA; The MIT Press.

Suchman, L. (1987). Plans and situated actions: The problem of human-machine communication. Cambridge, UK: Cambridge University Press.

Tedlock, B. (2000). Ethnography and ethnographic representation. In N. Denzin \& Y. Lincoln (Eds.), The handbook of qualitative research (pp. 455-486). Thousand Oaks, CA: SAGE.

Travica, B. (1999). New organizational designs: Information aspects. Stamford, CT: Ablex.

Travica, B. (2003). Information view of organization: Contextualizing technology - technologizing context. Proceedings of the American Conference for Information Systems, Tampa, FL, August 2003, nominated for The Best Paper Award.

Yin, R. (2003). Case study research: Design and methods ( $3^{\text {rd }}$ ed.). Thousand Oaks, CA: SAGE.

Zuboff, S. (1984). In the age of the smart machine: The future of work and power. BasicBooks.

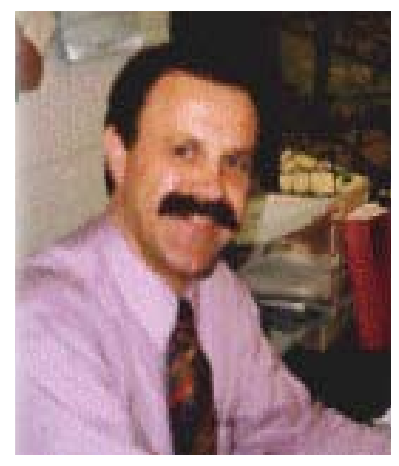

\section{Biography}

Bob Travica is an assistant Professor in management information systems, University of Manitoba, Canada. He taught at Indiana University 1994-2001. Ph.D. Degree from Syracuse University 1995. Reached academic waters after metamorphosing through several careerssoftware development, corporate communications, journalism, and folk dancing. Traveled the world, and loved it. Research interests include new organizational designs, e-commerce, international information systems, and information view of organization. 